\title{
Effects of Coatings on the High-Cycle Fatigue Life of Threaded Steel Samples
}

\author{
Eder, Martin Alexander; Haselbach, Philipp Ulrich; Mishin, O. V.
}

Published in:

Journal of Materials Engineering and Performance

Link to article, DOI:

$10.1007 / \mathrm{s} 11665-018-3399-2$

Publication date:

2018

Document Version

Peer reviewed version

Link back to DTU Orbit

Citation (APA):

Eder, M. A., Haselbach, P. U., \& Mishin, O. V. (2018). Effects of Coatings on the High-Cycle Fatigue Life of Threaded Steel Samples. Journal of Materials Engineering and Performance, 27(6), 3184-3198. https://doi.org/10.1007/s11665-018-3399-2

\section{General rights}

Copyright and moral rights for the publications made accessible in the public portal are retained by the authors and/or other copyright owners and it is a condition of accessing publications that users recognise and abide by the legal requirements associated with these rights.

- Users may download and print one copy of any publication from the public portal for the purpose of private study or research.

- You may not further distribute the material or use it for any profit-making activity or commercial gain

- You may freely distribute the URL identifying the publication in the public portal 


\title{
Effects of coatings on the high cycle fatigue life of threaded steel samples
}

\author{
M.A. Eder ${ }^{1 *}$, P.U. Haselbach ${ }^{1}$, O.V. Mishin ${ }^{2}$ \\ ${ }^{1}$ Department of Wind Energy, Technical University of Denmark, 4000 Roskilde, Denmark \\ ${ }^{2}$ Department of Mechanical Engineering, Technical University of Denmark, 2800 Kgs. Lyngby, \\ Denmark
}

\begin{abstract}
In this work, high cycle fatigue is studied for threaded cylindrical high strength steel samples coated using three different industrial processes: black oxidation, normal temperature galvanisation and high temperature galvanisation. The fatigue performance in air is compared with that of uncoated samples. Microstructural characterisation revealed the abundant presence of small cracks in the zinc coating partially penetrating into the steel. This is consistent with the observation of multiple crack initiation sites along the thread in the galvanised samples, which led to crescent type fracture surfaces governed by circumferential growth. In contrast, the black oxidised and uncoated samples exhibited a semicircular segment type fracture surface governed by single-sided growth with a significantly longer fatigue life. Numerical fatigue life prediction based on an extended Paris-law formulation has been conducted on two different fracture cases: 2D axisymmetric multisided crack growth and 3D single sided crack growth. The results of this upper-bound and lower-bound approach are in good agreement with experimental data and can potentially be used to predict the lifetime of bolted components.
\end{abstract}

Keywords: High strength steel bolts, High cycle fatigue failure analysis, Coating, Cracks, Life prediction, Modelling and simulation, Microscopy

*M.A. Eder | maed@dtu.dk | www.vindenergi.dtu.dk 


\section{Nomenclature}

\begin{tabular}{|c|c|c|}
\hline Symbol & Unit & Description \\
\hline$a$ & $\mathrm{~mm}$ & Crack length \\
\hline$a_{0}$ & $\mathrm{~mm}$ & Intrinsic crack length \\
\hline$a_{c}$ & $\mathrm{~mm}$ & Critical crack length at fracture \\
\hline$a_{e}$ & $\mathrm{~mm}$ & Effective crack length \\
\hline$a_{i}$ & $\mathrm{~mm}$ & Crack length increment \\
\hline$a_{i n i}$ & $\mathrm{~mm}$ & Initial crack length \\
\hline$b$ & & Basquin law exponent \\
\hline$c$ & $\mathrm{~mm}$ & Notch depth \\
\hline$d$ & $\mathrm{~mm}$ & Nominal diameter or diameter of steel core \\
\hline$d_{2}$ & $\mathrm{~mm}$ & Pitch diameter \\
\hline$r_{e}$ & $\mathrm{~mm}$ & Effective radius \\
\hline$k_{t}$ & & Theoretical stress concentration factor \\
\hline$l_{c}$ & $\mathrm{~mm}$ & Distance between cracks in coating \\
\hline$n, p, q$ & & Stage-1, Stage-2 and Stage-3 growth exponents \\
\hline$n_{x}, n_{y}$ & & Number of divisions in $\mathrm{x}$-direction and $\mathrm{y}$-direction respectively \\
\hline$r$ & $\mathrm{~mm}$ & Notch root radius \\
\hline$t_{c}$ & $\mathrm{~mm}$ & Coating thickness \\
\hline$x, y$ & $\mathrm{~mm}$ & Cartesian coordinates in the crack plane \\
\hline$A_{\text {eff }}$ & $\mathrm{mm}^{2}$ & Effective cross sectional area \\
\hline$C_{t h}, C$ & & Stage-1 and Stage-2 growth parameter \\
\hline $\bar{C}$ & & Basquin law parameter \\
\hline$E_{c}$ & MPa & Elastic modulus of zinc coating \\
\hline$E_{S}$ & $\mathrm{MPa}$ & Elastic modulus of steel (substrate) \\
\hline$F_{a}$ & $\mathrm{kN}$ & Load amplitude \\
\hline$F_{m}$ & $\mathrm{kN}$ & Mean load \\
\hline$G_{\max }, G_{c}$ & $\mathrm{~J} / \mathrm{mm}^{2}$ & Maximum Mode-1 SERR at peak load or critical SERR release rate \\
\hline$K_{c}$ & $\mathrm{MPa} \sqrt{m m}$ & Fracture toughness of steel material \\
\hline$K_{\max }$ & $\mathrm{MPa} \sqrt{m m}$ & Maximum stress intensity factor at peak load \\
\hline$K_{o p}$ & $\mathrm{MPa} \sqrt{m m}$ & Opening stress intensity factor \\
\hline$L$ & $\mathrm{~mm}$ & Length \\
\hline$N, N_{t o t}$ & & Number of cycles, number of cycles to failure \\
\hline$R$ & & Load ratio/ R-ratio \\
\hline$T$ & $\mathrm{~K}$ & Ambient temperature \\
\hline$T_{\text {sol }}$ & $\mathrm{K}$ & Solidification temperature of coating \\
\hline$X, Y, Z$ & $\mathrm{~mm}$ & Cartesian coordinates in the sample coordinate system \\
\hline$A$ & & $\begin{array}{l}\text { Constraint factor } \alpha=1 \text { for plane stress or crack closure } \\
\text { parameter or tensile stress concentration pre-factor } \alpha=2\end{array}$ \\
\hline$\alpha_{c}$ & $\mathrm{~K}^{-1}$ & Linear coefficient of thermal expansion of coating \\
\hline$\alpha_{s}$ & $\mathrm{~K}^{-1}$ & Linear coefficient of thermal expansion of substrate \\
\hline$\varepsilon_{i j}$ & & Green strain tensor \\
\hline$\delta_{i j}$ & & Kronecker delta \\
\hline$\Delta \alpha$ & $\mathrm{m}$ & Incremental crack spacing or fracture quantum \\
\hline
\end{tabular}




$\begin{array}{lll}\Delta \sigma & \mathrm{MPa} & \text { Stress range } \\ \Delta \sigma_{e} & \mathrm{MPa} & \text { Endurance limit range } \\ \Delta K & \mathrm{MPa} \sqrt{m m} \text { Stress intensity factor range } \\ \Delta K_{1} & \mathrm{MPa} \sqrt{m m} \text { Stress intensity factor threshold range for } \mathrm{R}=1 \\ \Delta K_{t h} & \mathrm{MPa} \sqrt{m m} \text { Stress intensity factor threshold range for } \mathrm{R} \geq 0 \\ v & & \text { Poisson's ratio } \\ \sigma_{0} & \mathrm{MPa} & \text { Flow stress of parent material } \\ \sigma_{a} & \mathrm{MPa} & \text { Nominal stress amplitude } \\ \sigma_{e} & \mathrm{MPa} & \text { Endurance limit amplitude } \\ \sigma_{m} & \mathrm{MPa} & \text { Nominal mean stress } \\ \sigma_{\max } & \mathrm{MPa} & \text { Maximum nominal stress level } \\ \sigma_{\min } & \mathrm{MPa} & \text { Minimum nominal stress level } \\ \sigma_{u} & \mathrm{MPa} & \text { Nominal ultimate tensile strength } \\ \sigma_{y} & \mathrm{MPa} & \text { Nominal yield strength } \\ \sigma_{T} & \mathrm{MPa} & \text { Maximum thermal equi-biaxial stress in coating }\end{array}$




\section{Introduction}

High-strength medium-carbon steel bolts are widely used in bolted friction grip connections. In wind turbines, high strength bolts are applied to connect primary structural components such as tower segments, generator bases, rotor blade roots, etc., which are typically subjected to high- and ultrahigh cyclic loading regimes with expected life spans in the order of $10^{6}$ to $10^{10}$ loading cycles. Proprietary maintenance reports indicate that the fatigue failure of bolts resides among the most frequent causes for the catastrophic failure of wind turbines, which poses a safety hazard and has significant cost implications. The apparent fact that the predicted fatigue lifetime of bolts in wind turbines is frequently overestimated suggests that current design approaches are non-conservative and emphasise a strong demand for the development of improved modelling tools. The use of reliable and computationally efficient fatigue life time prediction tools is two-fold: Firstly, they are highly relevant for the design of bolted connections, and secondly they serve the purpose of predicting the remaining lifetime as an essential part of inspection planning.

The fatigue failure of bolted connections involves several different issues, such as understressing, overstressing, loss of pre-stress (e.g. relaxation, fretting), corrosion and hydrogen embrittlement etc., which makes its investigation inherently complex. One important issue concerns the detrimental effect of commercially available coating systems, in particular hot-dip galvanisation (HDG), on the fatigue life of high-strength steels. The detrimental effect of HDG is deemed to be associated with temperature effects on the microstructure and the presence of cracks in the zinc coating.

Interestingly, in the case of hot-dip galvanised steel sheets, opposing views were reported regarding the influence of the coating thickness on the fatigue life. Bergengren and Melander (Ref 1) found that the fatigue life decreased with increasing coating thickness, whereas Nilsson et al. (Ref 2) concluded that there was no strong correlation between the coating thickness and fatigue properties. 
It should be noted that the different authors investigated steel alloys, which were very different in strength, and thus the results obtained on low- to medium-strength steel by Nilsson et al. (Ref 2) cannot be directly compared with those obtained for the higher-strength steel in Ref 1 .

Oechsner et al. (Ref 3) investigated the fatigue performance of M36 grade 10.9 high strength steel bolts coated using black oxidisation, normal temperature HDG and high temperature HDG. These authors found that hot-dip galvanised bolts exhibited a significantly shorter fatigue life compared to the oxidised ones. Cracks in the coating were identified as the origin of premature fatigue crack initiation in their bolts (Ref 3$)$.

In a recent study, Schaumann and Eichstädt (Ref 4,5) experimentally and numerically investigated the fatigue life of M36 and M64 grade 10.9 bolts used for ring-flange connections in wind turbine towers. A fatigue life diminishing effect due to HDG was found, and the authors concluded that the S-N curves stipulated in EN 1993-1-9 (Ref 6) were safe but rather conservative. Schaumann and Eichstädt (Ref 4,5) used stress analysis of an axisymmetric finite element model together with a method denoted as the local notch strain approach in order to predict the crack initiation lifetime of the entire bolt-nut assembly. According to Schneider (Ref 7), in the local notch strain approach a strain amplitude can be calculated based on the cyclic Ramberg-Osgood stressstrain curve formulation as a function of a static and dynamic hardening exponent.

The local notch strain approach is strictly speaking only applicable for the crack initiation phase with small cracks. To allow investigations of the crack size effect, a fracture based analysis approach is adopted in the present work. In this approach, the presence of small cracks prior to initial loading is assumed. This assumption is in agreement with scanning electron microscopy (SEM) observations of the thread root surface. Application of numerical fracture analysis to an extended version of the Paris-law allows for the investigation of spatial and temporal (in terms of lifetime) evolutions of crack growth and also for long range cracks until failure. 
The purpose of the present work is to identify two limiting fracture modes, which represent an upper bound and a lower bound to the fatigue life of high-strength bolts, and which can be used to estimate the remaining lifetime of bolted connections. Application of the aforementioned method for different stress amplitudes is used in this work to numerically predict $\mathrm{S}-\mathrm{N}$ curves in order to investigate the impact of different coating processes and the coating thickness on the fatigue life of threaded cylindrical steel samples. These samples are considered to be model bolts in the present work. The numerical results are validated against uniaxial constant amplitude fatigue test data obtained on thread-notched samples coated using three different industrial coating processes. The reason for the use of notched samples is to exclude effects originating from complex bolt-to-nut interactions. This simplification allows the strain to be localised in the thread notch, which facilitates strain measurements and the investigation of the effect of different coatings on the fatigue failure mode. Analytical fracture based solutions are used here to corroborate the crack spacing in the zinc coating, as well as analysing the effect of the coating thickness on the endurance limit.

\section{Experimental procedure}

\subsection{As-received material}

All samples described in this paper were produced from commercially available $\mathrm{M} 20 \times 280$ grade 10.9 black-oxidised high strength bolts with the following main alloying elements: $0.35 \mathrm{C}-0.78 \mathrm{Mn}-$ 0.18Si-0.17Cr (wt.\%), as measured using optical emission spectroscopy. Tensile tests conducted on dogbone shaped specimens machined from the bolts indicated that the mean $0.2 \%$ proof stress and the mean ultimate strength were $1060 \mathrm{MPa}$ and $1110 \mathrm{MPa}$ respectively. These values were respectively $\sim 18 \%$ and $\sim 11 \%$ higher than the values specified by the manufacturer for the 10.9 grade bolts (see Table 1). 


\subsection{Machining and coating}

To ensure that failure during fatigue tests occurs in the designated gauge section, a thread was milled into the $210 \mathrm{~mm}$ long shank at mid-length using a 5-axis computer numerical control milling machine. The thread consisted of a half turn lead-in followed by a full turn and a half turn run-out (Fig. 1).

An example of the as-machined (AM) specimens with uncoated threads is shown in Fig. 1a. Twenty such specimens were industrially coated using three different coating procedures: (i) HDG at a conventional normal temperature (NTG samples); (ii) HDG at a high temperature (HTG samples); and (iii) black-oxidation (BO samples), see Fig. 1b-d. The exact processing details of each coating procedure were not disclosed to the authors. Based on the literature data, it is considered that the bath temperature was approximately $450{ }^{\circ} \mathrm{C}$ in the NTG process and in the range of $560{ }^{\circ} \mathrm{C}$ to $630{ }^{\circ} \mathrm{C}$ in the HTG process. The processing temperature for the $\mathrm{BO}$ samples is expected to be approximately $180^{\circ} \mathrm{C}$.

\subsection{Fatigue testing}

Fatigue testing was conducted using a servo-hydraulic uniaxial Instron 88R8033 machine having an Instron H0310-UK 004 load cell with a capacity of $250 \mathrm{kN}$, see Fig. 2a. Three specimens were tested for each type of the coated samples, while six specimens were tested for the AM series. Each specimen was held by two hydraulic grips on either side, and the strain was measured using two clip extensometers along a gauge length of $10 \mathrm{~mm}$ across the threaded notch. The extensometers were positioned in such a way that the left hand side extensometer measured the displacement across two notches, while the right hand side extensometer measured the displacement across a single notch (Fig. 2a). The turning points of the load and strain signals were recorded.

Prior to fatigue testing the specimens were pre-loaded in tension to the nominal bolt pre-stress of $\sigma_{m}=0.7 \sigma_{y}$ (Table 1) as stipulated in Ref 8,9. A harmonic constant amplitude fatigue load was 
subsequently applied in force control at $20 \mathrm{~Hz}$ until fracture. The nominal stress amplitude applied in this work was chosen to be $90 \mathrm{MPa}$, which was close to the endurance limit of the notched $\mathrm{BO}$ specimens tested by Oechsner et al. (Ref 3$)$.

\subsection{Hardness measurements}

One untested specimen from each series was sectioned along the longitudinal axis and mechanically polished. Vickers hardness (HV) was measured in this polished section using a Struers DuraScan tester along 19 lines spaced at a distance of $\sim 1 \mathrm{~mm}$. For each line, fifteen individual measurements were performed using a load of $3 \mathrm{~kg}$ and a dwell time of $15 \mathrm{~s}$. Additionally, HV measurements were performed in the thread root after the crest and the flank were ground. For these measurements a load of $2 \mathrm{~kg}$ was applied perpendicular to the root surface. The galvanised samples were ground to reach the steel surface in the thread root.

\subsection{Microscopy}

The longitudinal section of the samples was mechanically polished and then investigated in a Zeiss Supra 35 scanning electron microscope using a secondary electron detector. Images of the fracture surface after fatigue testing were taken using a high-resolution digital camera (see Subsection 5.3).

\section{Numerical fracture analysis}

All finite element (FE) calculations were performed using the commercially available software Abaqus CAE (Ref 10). The geometry of the FE-model of the samples used in this work is depicted in Fig. 3. Three different FE-models were created: an exact 3D model of the specimen with a thread notch (Fig. 4a); a 3D model with a single circumferential notch (Fig. 4b); and an axisymmetric model (Fig. 4c) which corresponds to the 3D model with the circumferential notch.

\subsection{D model with a threaded notch}

The thread geometry of the exact model was created in SOLIDWORKS 3D CAD (Ref 11) and Page 8 
subsequently imported into Abaqus CAE. In order to extract stresses along predefined paths, the bolt model was partitioned at several locations.

For the sake of computational efficiency, preliminary studies were conducted to determine a minimum bolt length in order to avoid boundary effect interference in the area of interest. This minimum length was found to be $50 \mathrm{~mm}$. The exact 3D model was discretised with $10^{6}$ eight-node linear brick elements with reduced integration and hourglass control (Abaqus element type C3D8R) and $7.3 \times 10^{5}$ ten-node quadratic tetrahedron elements (Abaqus element type C3D10). Thus, the total number of elements was approximately $2 \times 10^{6}$. The characteristic element length was $2.5 \times 10^{-}$ ${ }^{2} \mathrm{~mm}$. Isotropic, homogeneous, linear elastic-material properties for steel were assigned to all models with $E_{S}=210 \mathrm{GPa}$ and $v=0.3$. The adopted elasticity parameters for the zinc coating were $E_{c}=108 \mathrm{GPa}$ and $v=0.25$ respectively.

For the stress analysis of the exact 3D model, a linear perturbation solver was applied. All FE models were loaded in force-control along the bolts axis (Y-direction in Fig.3) through a master node located in the centre associated with a Multi Point Constraint applied to the upper surface. In each model the degrees of freedom of the lower surface were constrained in the Y-direction without restraining lateral deformation with additional constraints avoiding rigid body motions.

\subsection{D model with single circumferential notch}

Our preliminary numerical analysis revealed that the stress levels and stress distribution in the threaded-notch model closely matched those predicted for the circumferential notch model. Therefore, the 3D circumferential notch model was used for numerical fracture analysis, which allowed a higher mesh quality due to the symmetric geometry, as opposed to the threaded notch model. The 3D model was discretised with Abaqus C3D8R elements. This element type supports the Virtual Crack Closure Technique (VCCT) (Ref 12) used to compute the Strain Energy Release Rate 
(SERR) for different crack stages.

The upper and lower halves were modelled separately and connected via tie constraints, as shown in Fig. 4b. Surface-to-surface, hard, frictionless contact conditions were assigned to the interface, defined as the crack plane, to avoid interpenetration of the crack flanks. The crack plane was located in the notch root with its outward normal aligned with the loading axis. Cracks with linear and parallel crack fronts (see Fig. 5a) were simulated by disconnecting the corresponding nodes of the crack faces by limiting the bonding to a subset of nodes. The model was consecutively solved for different crack lengths, i.e. intermediate crack stages of $\Delta a=0.1 \mathrm{~mm}$ with an initial crack length of $1.25 \times 10^{-2} \mathrm{~mm}$ and a final crack length of $12 \mathrm{~mm}$ corresponding to $a_{c}$. The geometry was discretised with an element length ranging between $0.025 \mathrm{~mm}$ and $0.125 \mathrm{~mm}$. The model had a total number of $1.2 \times 10^{6}$ elements, where a Newton-Raphson solver was adopted for fracture analysis.

\subsection{Axisymmetric model}

Figure 4c shows the axisymmetric model constructed with three different zinc coating layer thicknesses: $30 \mu \mathrm{m}, 60 \mu \mathrm{m}$ and $90 \mu \mathrm{m}$. The geometries were discretised with approximately $9 \times 10^{5}$ four-node bilinear axisymmetric elements with reduced integration and hourglass control (Abaqus type CGAX4R) with a characteristic element length of $2.5 \times 10^{-3} \mathrm{~mm}$. The model was solved for intermediate crack stages of $\Delta a=0.1 \mathrm{~mm}$ with a final crack length of $5 \mathrm{~mm}$. Loading, boundary conditions, mesh refinement and solver were identical to those described in Subsections 3.1 and 3.2.

\subsubsection{Simulation of fatigue crack growth}

Fatigue crack growth was modelled using the NASGRO equation (Ref 13) originally proposed by Forman et al. (Ref 14). Equation 1 represents an extended version of the Paris-law which also takes into consideration Stage-1 (near threshold) as well as Stage-3 (near fracture) crack growth. 


$$
\frac{d a}{d N}=g(a)=C\left[\left(\frac{1-f(R)}{1-R}\right) \Delta K\right]^{n} \frac{\left(1-\frac{\Delta K_{t h}}{\Delta K}\right)^{p}}{\left(1-\frac{K_{\max }}{K_{C}}\right)^{q}}
$$

The crack opening function $f(R)$ proposed by Newman (Ref 15) considers crack closure and can be written for $R \geq 0$ as follows:

$$
f(R)=\frac{K_{o p}}{K_{\max }}=\max \left(R, A_{0}+A_{1} R+A_{2} R^{2}+A_{3} R^{3}\right)
$$

with the coefficients defined as follows:

$$
\begin{aligned}
& A_{0}=\left(0.82-0.34 \alpha+0.05 \alpha^{2}\right)\left[\cos \left(\frac{\pi \sigma_{\max }}{2 \sigma_{0}}\right)\right]^{1 / \alpha} \\
& A_{1}=(0.415-0.071 \alpha) \frac{\sigma_{\max }}{\sigma_{0}} \\
& A_{2}=1-A_{0}-A_{1}-A_{3} \\
& A_{3}=2 A_{0}+A_{1}-1
\end{aligned}
$$

The threshold stress intensity factor (SIF) range for $R \geq 0$ was considered as follows:

$$
\begin{aligned}
& \Delta K_{t h}=\frac{\Delta K_{1}^{*}}{\left(1-A_{0}\right)^{(1-R) C_{t h}}}\left[\frac{1-R}{1-f(R)}\right]^{1+R C_{t h}} \\
& \Delta K_{1}^{*}=\Delta K_{1} \sqrt{\frac{a}{a+a_{0}}}
\end{aligned}
$$

Eq (9) was used to convert the SERR values obtained through VCCT into corresponding SIFs assuming plane strain conditions. Subsequently, Eq (10) was used to obtain the SIF range for every single crack stage.

$$
\begin{aligned}
& K_{\max }=\sqrt{\frac{G_{\max } E_{S}}{1-v^{2}}} \\
& \Delta K=\frac{K_{\max }}{\sigma_{\max }}\left(\sigma_{\max }-\sigma_{\min }\right)
\end{aligned}
$$

The fatigue lifetime was obtained by numerical integration of Eq (1) using the trapezoidal rule for uniform spacing as follows: 


$$
N=\int_{a_{\text {ini }}}^{a_{c}} \frac{1}{g(a)} d a \approx \frac{a_{c}-a_{i n i}}{2 m} \sum_{i=1}^{m}\left(\frac{1}{g\left(a_{i+1}\right)}-\frac{1}{g\left(a_{i}\right)}\right)
$$

The initial crack length $a_{i n i}=15 \mu \mathrm{m}$ was chosen according to the average crack length in the steel substrate measured in the SEM images. It is assumed that the initial crack length is below a size that remains undetected by typical on-site inspection methods. The critical crack length $a_{\mathrm{c}}$ was obtained by satisfying the condition $K_{\max }=K_{c}$.

Since the literature search did not result in finding the specific fracture and fatigue parameters of the bolt material, for fatigue life predictions these parameters were taken for a material with the closest match of the yield strength, namely ASTM A400 steel (see Table 2), selected from the NASGRO database (Ref 16). It should be mentioned that the parameters were not calibrated against the test data in the numerical analysis. The simulation of fatigue crack growth was divided into two different modelling approaches representing an upper and lower bound approximation for the fatigue lifetime. The first approach depicted in Fig. 5a is denoted as single-sided crack growth and assumes that fatigue cracks propagate upwards along the y-direction with parallel crack fronts. The second approach depicted in Fig. 5b is denoted as multisided crack growth and assumes that fatigue cracks propagate in the radial direction with concentric crack fronts. For single-sided fatigue crack growth simulation, the locally weighted scatter plot LOWESS in Matlab (Ref 17) was used to fit a smooth surface to the nodal $K_{\max }(\mathrm{x}, \mathrm{y})$ values obtained from Eq (9) associated with the different crack stages. The $\Delta K(\mathrm{x}, \mathrm{y})$ surface was consequently obtained in a similar way through scaling of the $K_{\max }(\mathrm{x}, \mathrm{y})$ values according to $\mathrm{Eq}(10)$. The crack fronts were divided into $n_{x}=101$ crack paths and every $\Delta a$ was divided into $n_{y}=20$ intervals. The numbers of cycles to failure $N_{i}$ for every integration path was computed using Eq (11) by the numerical integration tool available in Matlab (Ref 17). Figure 6 shows the integration path scheme. The total number of cycles to failure $N_{t o t}$ of the single-sided growth case was computed using Eq (12). 


$$
N_{t o t}=\frac{N_{1}+\sum_{i=2}^{n_{x}} N_{i}}{2 n_{x}-1}
$$

where $N_{1}$ is associated with the integration path along the y-axis.

In the case of multisided crack growth simulation, a procedure similar to that adopted for the single-sided approach was used. However, a third order spline was used instead of a surface to fit the nodal $K_{\max }$ values of the different crack stages obtained by VCCT applied to the axisymmetric model. Due to the $2.5 \mathrm{D}$ nature of the axisymmetric model only one integration path was necessary to compute the number of cycles to failure.

\section{Analytical investigation of crack spacing and endurance limit}

Owing to the mismatch of the thermal coefficients of expansion between the zinc coating and steel substrate, thermal strains and stresses are induced into the coating during cooling (Ref 18). Assuming a rigid thick substrate, the strain in the coating can be written as follows:

$$
\Delta \epsilon_{i j}=\left(T-T_{s o l}\right)\left(\alpha_{c}-\alpha_{s}\right) \delta_{i j}=\Delta T \Delta \alpha \delta_{i j}
$$

For a thin zinc film coating, it can reasonably be assumed that the strains in the coating are uniform through the thickness and that the contraction of the zinc coating has no significant effect on the substrate. Figure 7a depicts the tensile strain and stress direction in the coating layer. Since the coating is free to shrink in the thickness direction, plane stress conditions can be assumed such that $\sigma_{33}=\sigma_{31}=\sigma_{23}=0$. The thermally induced stress state is governed by biaxial tension $\sigma_{11}=\sigma_{22}$ and $\sigma_{12}=0$. The equibiaxial thermal stress component can consequently be written as follows:

$$
\sigma_{T}=\frac{E_{C}}{1-v} \Delta \alpha \Delta T
$$

Upon solidification intermetallic phases are formed inside the zinc coating, where the $\delta$ phase is the most brittle one and closest to the substrate (Ref $1,2,18)$. It is generally accepted that $\sigma_{T}$ induces a periodic arrangement of surface cracks in the coating layer as schematically depicted in Fig. 7a. For 
simplicity, the properties of commercially pure zinc were adopted in the present work for the entire coating during simulations.

The literature provides several closed form solutions for periodic crack arrays initiating from the surface. Such surface crack models can be used to grossly estimate the fracture toughness of the zinc coating based on the measured crack spacing $l_{c}$ and coating thickness $t_{c}$ (see Fig. 7a,b). According to Hutchinson and Suo (Ref 19), the steady state SIF of a periodic array of single edge cracks in a monomaterial coating layer can be written as:

$$
K_{c}=\sigma_{T} \sqrt{1.98 t_{c}} \text { for } l_{c} \geq 8 t_{c} \text { and } \sigma_{T} \leq \sigma_{u}
$$

According to Thouless (Ref 20), Eq (15) represents the initiation criterion for cracks with noninteracting near-tip stress fields for a stage where the crack tips still remain in the zinc layer remote from the interface. A further increase of the tensile stress induces new cracks in between the existing cracks. Thouless (Ref 20) proposes an expression for a critical SIF which considers mutual screening of the near-tip stress fields as follows:

$$
K_{c}=\sigma_{T} \sqrt{\frac{l_{c}}{2}-0.0316 \frac{l_{c}^{2}}{t_{c}}} \quad \text { for } l_{c} \geq 8 t_{c} \quad \text { and } \sigma_{T} \leq \sigma_{u}
$$

In another publication, Thouless et al. (Ref 21) used an energy based approach to obtain the equilibrium crack spacing by considering the effect of sequential crack formation, as opposed to simultaneous crack formation (Ref 20). For $K_{I c}=\sqrt{G_{c} E_{c}}$ the critical SIF can be written as follows:

$$
K_{c}=\frac{l_{c}}{5.6} \sqrt{\frac{\sigma_{T} E_{c}}{t_{c}}} \quad \text { for } \sigma_{T} \leq \sigma_{u}
$$

Xia and Hutchinson (Ref 22) considered the elastic mismatch of the bi-material interface by introducing a characteristic length $\lambda=\pi g(\alpha, \beta) t_{c} / 2$ with $g(\alpha, \beta)$ being the dimensionless integral of the crack opening displacement introduced by Beuth (Ref 23). The proposed solution is given in Eq (18) and represents a stage where the crack tip is located in the bi-material interface. It is 
noteworthy that the function $g(\alpha, \beta)$ is governed by $\alpha$ and only weakly depends on $\beta$.

$$
K_{c}=\sigma_{T} \sqrt{\left(1-v^{2}\right) \lambda \tanh \left(\frac{l_{c}}{2 \lambda}\right)} \quad \text { for } \sigma_{T} \leq \sigma_{u}
$$

In order to qualitatively investigate the effect of the coating thickness on the circumferential crack growth, it is assumed that there is an initial predominant crack which penetrates into the substrate, as depicted in Fig. 7d. The bi-material (steel/coating in the present case) problem can be simplified into a mono-material problem by converting the thickness of the zinc coating into an equivalent steel thickness using a conversion factor $\eta$, upon which the corresponding equivalent crack length $a_{e}$ and effective radius $r_{e}$ can be calculated as follows:

$$
\begin{aligned}
& \eta=\frac{E_{c}}{E_{s}} \\
& a_{e}=a_{i n i}+\eta t_{c} \\
& r_{e}=d / 2+\eta t_{c}
\end{aligned}
$$

Equation 22 represents the closed form solution for the SIF threshold of a circumferential crack in a cylindrical shaft taken from Tada et al. (Ref 24).

$$
\Delta K_{t h}\left(a_{e}\right)=\Delta \sigma \sqrt{\pi a_{e}} \frac{1}{\left(1-a_{e} / r_{e}\right)^{3 / 2}}\left(1.122-1.0302 \frac{a_{e}}{r_{e}}+9.88\left(\frac{a_{e}}{r_{e}}\right)^{2}-0.308\left(\frac{a_{e}}{r_{e}}\right)^{3}\right)
$$

Using the generalised Paris-law formulation from Ref 25,26 the mean value of the SIF threshold given by Eq (22) can be written as follows:

$$
\Delta K_{t h}^{*}\left(a_{e}\right)=\sqrt{\frac{1}{\Delta a} \int_{a_{e}}^{a_{e}+\Delta a} \Delta K_{t h}\left(a_{e}\right) d a_{e}}=1.122 \Delta \sigma \sqrt{\frac{r_{e}^{3}\left(\left(a_{e}+\Delta a / 2\right) r_{e}-a_{e}\left(a_{e}+\Delta a\right)\right)}{\left(r_{e}-a_{e}\right)^{2}\left(r_{e}-a_{e}-\Delta a\right)^{2}}}
$$

Note that the last three terms in the brackets of Eq (22) can be neglected assuming that the initial crack length is small compared to the bolt diameter $a_{e} / r_{e} \ll 1$. The fracture quantum $\Delta a(\operatorname{Ref} 26)$ can be isolated from Eq (23) by letting $a_{e} \rightarrow 0$ and equating the material fatigue threshold $\Delta K_{t h}$ with $\Delta K_{t h}^{*}\left(a_{e}\right)$ and by substituting $\Delta \sigma$ with $\Delta \sigma_{e}$ as follows: 


$$
\Delta a=\frac{r_{e}}{4 \Delta K_{t h}^{2}}\left(1.122^{2} \pi r_{e} \Delta \sigma_{e}^{2}+4 \Delta K_{t h}^{2}-\sqrt{1.22^{4} \pi^{2} r_{e}^{2} \Delta \sigma_{e}^{4}+8 \pi 1.122^{2} r_{e} \Delta K_{t h}^{2} \Delta \sigma_{e}^{2}}\right)
$$

The endurance limit range $\Delta \sigma$ can eventually be obtained by recasting Eq (23) upon substitution of $\Delta K_{t h}^{*}\left(a_{e}\right)=\Delta K_{t h}$ as follows:

$$
\Delta \sigma=\frac{2\left(r_{e}-a_{e}-\Delta a\right)\left(r_{e}-a_{e}\right) \Delta K_{t h}}{1.122 \sqrt{\pi\left(4 r_{e}^{2} a_{e}+2 r_{e}^{2} \Delta a-4 r_{e} a_{e}^{2}-4 r_{e} a_{e} \Delta a\right)} r_{e}}
$$

The asymptote for large cracks can be obtained from Eq (23) by letting $\Delta a \rightarrow 0$ which can be written as follows:

$$
\Delta \sigma \approx \frac{\left(r_{e}-a_{e}\right)^{2} \Delta K_{t h}}{1.22 \sqrt{\pi r_{e} a_{e}\left(r_{e}-a_{e}\right)} r_{e}}
$$

\section{Experimental results}

\subsection{SEM characterization of coatings}

SEM images showing the coated threads in the longitudinal section are presented in Fig. 8. The thickness of the black oxide layer is less than $2 \mu \mathrm{m}$ and, therefore, it can hardly be distinguished in Fig. 8a,b. In contrast, the coatings produced during galvanisation are much thicker (see Fig. 8c-f). The coating thickness in the thread of the NTG sample is between $60 \mu \mathrm{m}$ and $70 \mu \mathrm{m}$. Furthermore, the thread of this sample is half-filled with redundant solidified zinc, which contains coarse pores. The total thickness of the coating and the redundant zinc layer in this thread is $0.7 \mathrm{~mm}$. A closer inspection reveals that the coating in the NTG sample contains multiple cracks (see Fig. 8d). The coating thickness of the HTG sample is slightly larger, $80 \mu \mathrm{m}$ to $100 \mu \mathrm{m}$, than that of the NTG sample. However, there is no redundant zinc retained in the thread due to a higher coating temperature, which lowers the zinc viscosity, thus allowing it to flow off more easily. Nevertheless, this coating also contains cracks (see Fig. 8e,f). Some of these cracks propagate into the steel over a distance of $5 \mu \mathrm{m}$ to $15 \mu \mathrm{m}$ (Fig. 9). 


\subsection{Vickers Hardness}

Vickers hardness of the AM sample and the coated samples is shown in Fig. 10 along the normalized distance from the surface. The green area in this figure corresponds to the standard range, $320 \mathrm{HV}$ to $380 \mathrm{HV}$, for grade 10.9 bolts as specified by the manufacturer. It is seen that the AM sample is characterised by the highest level of hardness. The hardness is slightly lower in the BO and NTG samples. Except for one data point in the NTG sample, the AM, BO and NTG lines are well within the standard range for the 10.9 grade bolts. However, the HTG sample is much softer than any other sample and its hardness is lower than the minimum hardness specified by the bolt manufacturer for the 10.9 grade. It is also apparent that in each sample, the hardness tends to be slightly lower near the centre and higher at the surface.

\subsection{Fatigue data}

As is evident from Fig. 11, each of the three coating processes results in a reduced fatigue life compared to the AM sample, with the greatest reduction seen for the galvanised samples. The average fatigue life of the NTG, HTG and BO samples corresponds to $24 \%, 36 \%$ and $78 \%$, respectively of the average fatigue life of the AM sample. Inspection of the fracture surface of the fatigue tested specimens (Fig. 12) reveals substantial differences between the different samples. Ratcheting marks are much more pronounced in the NTG sample than the marks in any other sample. In addition, light and dark areas can be distinguished on the fracture surfaces in this figure, where the light areas correspond to zones of fatigue crack initiation and growth, while the dark areas correspond to zones of fast fracture. It is apparent that the light areas resemble a half moon in the AM and BO samples (Fig. 12a,b), whereas a crescent moon pattern is seen in the galvanised samples (Fig. 12c,d).

Whether the crack surface resembles a half moon or a crescent moon can directly be inferred from the strain histories. Figure 13 shows the envelopes of the strain history turning points measured on both sides of the tested samples. For the majority of the samples, the initial maximum strain levels 
are higher on the left hand side, where the two notches provide a higher compliance. This is consistent with the numerical results of the 3D model with the threaded notch. The turning point envelopes of the strain history in Fig. 13 represent two distinct fracture behaviours observed for the different samples. Figure 13a shows that the fatigue crack initiated near the single notch (right hand side in Fig. 3). The crack propagation was single-sided and the crack grew towards the side with two notches (left hand side in Fig. 3). As the crack propagates, the strain on the single-notch side increases. Consequently, the strain levels on the two-notch side decrease due to bending effects. The strain level continues to decrease until it reaches a local minimum, after which it rapidly increases until fracture.

Figure $13 \mathrm{~b}$ shows a rather different behaviour, inasmuch at least two cracks develop on either side, as the difference between the maximum and minimum strains progressively increases. The NTG specimens typically showed a similar increase in strain on both sides, similar to that in Fig. 13b, whereas the AM and BO specimens showed a strain history similar to that in Fig. 13a. The HTG specimens showed an intermediate case between the two strain histories, presented in Fig. 13.

\section{Modelling results}

\subsection{D model with threaded notch}

The numerical simulation of the 3D model with a threaded notch for the maximum load predicts the highest stress concentrations in the notch root along the perimeter of the full thread turn as shown in Fig. 14. It is seen that the stress $S_{\mathrm{yy}}$ along the thread reaches its maximum at half of the perimeter length, and decreases towards the thread run-out. The predicted location of the maximum stress coincides with crack initiation locations typically observed in the experiment. Figure 14 shows that the stress state along the thread notch radius is multiaxial with $S_{\mathrm{xx}}, S_{\mathrm{zz}}$ and $S_{\mathrm{xz}}$ components following a periodic distribution. The numerically predicted notch stress concentration factor (SCF) for the $S_{\mathrm{yy}}$ component is 4.6, which agrees with the theoretical SCF $k_{t}=1+\alpha \sqrt{c / r}=4.7$ (Ref 27). Figure 15 
compares normalised von Mises stress distributions for the axisymmetric model and the 3D model with the threaded notch under maximum load. Stress paths are taken in the cross-sections at different locations along the longitudinal bolt axis. Figure 15 demonstrates agreement between the two models, which justifies the use of the axisymmetric model for fracture analysis. The stress distribution along the notch root in Fig. 15 suggests that a local plastic zone with an estimated inplane size of $0.5 \times 0.7 \mathrm{~mm}$ has formed in front of the notch radius under nominally elastic loading conditions.

Figure 16 shows a contour plot of the $K_{\max }$ surface obtained from single-sided growth analysis. The gradient in the y-direction parallel to the crack front is rather small in the centre and rapidly increases towards the boundary defined as the circular outer perimeter of the notch. The close spacing between the dashed lines indicates that the gradient in the crack propagation direction is significant for small crack lengths $a$. The gradient decreases towards the centre before it rapidly increases close to the critical crack length where fracture occurs. The SIF distribution for the axisymmetric case is qualitatively similar to the polynomial expression given by Eq (22) and is therefore not shown here. Figure 17 shows simulated S-N data for the two fatigue crack growth cases presented in Fig. 5 along with the experimental results. Different solid lines in Fig. 17 correspond to the three coating thicknesses considered in the axisymmetric simulations, whereas the dashed line corresponds to the single-sided crack growth case. For the applied stress amplitude of $90 \mathrm{MPa}$, the single-sided fatigue growth case overpredicts the fatigue life of the AM sample by $23 \%$. Conversely, the axisymmetric cases with $30 \mu \mathrm{m}, 60 \mu \mathrm{m}$ and $90 \mu \mathrm{m}$ coating thickness underpredict the fatigue life of the NTG sample by $25 \%, 28 \%$ and $39 \%$ respectively. Table 3 lists the Basquin parameters (Ref 28) obtained by curve-fitting of the power law $\sigma_{a}=C N^{b}$ The values are in close agreement with the slopes reported by Oechsner et al. (Ref 3), which were on average found to be 0.32 .

The critical crack length of the different fatigue growth cases can be identified by inspection of 
the fracture surfaces shown in Fig. 12. The critical crack length $a_{c}$ is defined here as the distance measured in the radial direction between the threaded edge and the onset of the fast fracture surface. The critical crack length predicted with the single-sided growth model was $a_{c}=11 \mathrm{~mm}$, which is in reasonable agreement with Fig. 12a,b. The critical crack length predicted with the axisymmetric growth model was $a_{c}=4.6 \mathrm{~mm}$, which is in reasonable agreement with Fig. $12 \mathrm{c}$.

\subsection{Analysis of cracks}

Substitution of $T_{\text {sol }}=418{ }^{\circ} \mathrm{C}$ for zinc and the two coefficients of thermal expansion $\alpha_{s}=10.5 \times$ $10^{-6}{ }^{\circ} \mathrm{C}^{-1}$ and $\alpha_{c}=35 \times 10^{-6}{ }^{\circ} \mathrm{C}^{-1}$ for steel and zinc respectively into Eq (14) yields a theoretical tensile stress magnitude of approximately $860 \mathrm{MPa}$. This stress magnitude significantly exceeds the ultimate tensile strength of zinc which is about $\sigma_{\mathrm{u}}=150 \mathrm{MPa}$ indicating a high likelihood of crack formation upon cooling.

The SEM analysis revealed that the average crack spacing $l_{\mathrm{c}}$ in the NTG sample was $100 \mu \mathrm{m}$, whereas for the HTG sample the crack spacing $l_{\mathrm{c}}$ was $80 \mu \mathrm{m}$. Calculation of the elastic mismatch factor proposed by Dundurs (Ref 29) for the present case yields $\alpha=\left(E_{\mathrm{c}}-E_{\mathrm{s}}\right) /\left(E_{\mathrm{c}}+E_{\mathrm{s}}\right)=-0.36$, which gives $g(\alpha, \beta) \approx 1$. Since the thermal stresses cannot exceed the tensile strength of zinc, $\sigma_{T}=\sigma_{u}$ was used in Eq (15 to 18$)$.

Table 4 shows that the calculated critical SIFs in the coating during initiation (i.e. no crack tip stress field interaction) and sequential secondary crack formation (i.e. under stress field screening) are between $8 \mathrm{MPa} \sqrt{m}$ to $1 \mathrm{MPa} \sqrt{m}$ for the NTG sample and in the range of $5 \mathrm{MPa} \sqrt{m}$ to $1 \mathrm{MPa} \sqrt{m}$ for the HTG sample. Figure 18 is a so-called Kitagawa diagram, which shows the effect of the coating thickness on the endurance limit according to Eq (25) for the same geometry parameters and material parameters used for the axisymmetric simulations. It shows that the endurance limit decreases when the coating thickness increases, which is consistent with Fig. 17. The solution for $a_{\text {ini }}=0$ approaches 
the endurance limit stress range $\Delta \sigma / \Delta \sigma_{\mathrm{e}}=1$ when the coating thickness approaches zero. Conversely, all solutions converge towards the asymptote given by Eq (26) for increasing coating thickness as well as for increasing initial crack size. Inspection of Eq (25) shows that a variation of the coating stiffness has the same effect, inasmuch as a decrease of the coating stiffness relative to that of the bolt material decreases the endurance limit knock-down. From this it can also be inferred that the coating thickness has a strong influence on stage-1 growth of the Paris-law regime (Eq (1)), which significantly affects the total lifetime.

\section{Discussion}

It is important to emphasize that the model bolt geometry applied in the present work deviated from the standard bolt geometry. Additionally, the threaded notch in the samples was machined, which is in contrast to the more commonly adopted rolled threads. These factors may have some influence on the fatigue performance of the particular samples as compared to commercially available bolts. The present study, however, is not intended for comparison with a particular bolt type, but aims at studying the effect of different coatings through a combination of experiments and numerical analysis. It is significant that all the samples were machined identically, and the only variable in their processing was the coating technique.

Our fatigue test results for these samples show that HDG considerably reduces the fatigue lifetime in air by up to $75 \%$ compared to the AM samples. In contrast, the BO coating process has only a little effect on the fatigue life. It is found that the performance of the HTG sample is slightly better than that of the NTG sample (see Fig. 11), which is different from the results presented by Oechsner et al. (Ref 3) for the notched specimens. However, our findings are consistent with those presented in Ref. 3 for M36 HTG and NTG bolts. It is interesting that the better fatigue performance of the HTG sample, as compared to the NTG sample, is observed despite the HTG material is 
considerably softer than the NTG material (Fig. 10). The latter is apparently caused by the higher galvanisation temperature for the HTG sample, which can facilitate more structural recovery along with microstructural coarsening (Ref 30,31), leading to significant softening.

According to Eq (27) presented by Garwood et al (Ref 32), a material with lower hardness and strength is expected to demonstrate a shorter fatigue life, which is not the case in the present experiment.

$\sigma_{e}=1.6 \mathrm{HV} \pm 0.1 \mathrm{HV} \quad$ for $\mathrm{HV} \leq 400$

Therefore, it appears that the difference in hardness alone is not sufficient to predict which coated sample will exhibit better fatigue performance. It is suggested that finely spaced cracks originating due to cooling-induced stresses after HDG can be the main reason for a reduced fatigue life of hot-dip galvanised steels (Ref 1,3$)$.

A number of small $(\leq 15 \mu \mathrm{m})$ thread root cracks were also observed in the steel substrate of the HTG sample (Fig. 9). These cracks were probably produced due to strain-age embrittlement when high stress areas, such as those in the thread root, were exposed to high temperatures during galvanisation. The estimated SIFs listed in Table 4 are considerably lower than those for commercially pure zinc (between $35 \mathrm{MPa} \sqrt{m}$ to $100 \mathrm{MPa} \sqrt{m}$ ). The magnitude of the values in Table 4 is comparable with $2 \mathrm{MPa} \sqrt{m}$ obtained by Reumont et al. (Ref 18), corroborating the detrimental effect of the brittle $\delta$ intermetallic phase.

The presence of coarser cracks in the coating may have assisted the process of cracking in the steel substrate. According to Tullock et al (Ref 33) the competition between crack deflection and penetration at a bi-material interface is governed by the ratio of the interface toughness to that of the substrate. The analysis of Fig. 5 in Tullock et al (Ref 33) suggests that with the prevailing elastic mismatch $\alpha=0.36$ surface cracks are likely to penetrate if the interface toughness exceeds only one quarter of the substrate toughness. This implies that the prevailing conditions represent a rather 
favourable situation for crack penetration.

It should be noted that the presence of cracks in the steel substrate due to HDG may have affected the toughness of the steel surface in such a way that crack penetration in the thread root becomes feasible. Our observations of cracks in the steel substrate are consistent with the previous reports for a number of different steels (Ref 1-3,34).

The fracture surface of the AM and BO samples shown in Fig. 12a,b exhibit a single-sided fatigue growth with a fairly uniform propagation from one side to the opposite side. This case is governed by the macrostress distribution with an initiation and growth pattern that follows a low frequency of surface cracks. On the other hand, for the galvanised samples in Fig. 12c,d fatigue growth occurred along the entire perimeter with radial propagation. In this case, strong singularities are distributed all over the thread, resulting in multiple crack initiation locations, and are largely independent of the macrostress distribution governed by the thread notch geometry.

Comparing Fig. 12a,b with Fig. 19a, it is evident that fracture surfaces of the AM and BO samples correspond to a mild stress concentration pattern as would be expected in a rounded defectfree notch according to Millela (Ref 35). In contrast, the fracture surface of the galvanised samples (Fig. 12c,d) resembles the pattern depicted in Fig. 19a for a case of severe stress concentrations. The latter is attributed the presence of multiple cracks in the coating and, for the HTG sample, also in the steel substrate. Therefore, it is suggested that Fig. 17, showing single-sided growth, represents an upper bound for the fatigue life of the tested samples, whereas the axisymmetric case represents a lower bound for the fatigue life. The latter is considered to represent a worst case scenario. Table 3 shows that the slopes in the S-N diagram are almost identical for all the cases analysed in the present work. However, both the intercepts and the estimated endurance limits are significantly lower in the axisymmetric growth case, as compared to the single-sided growth case. Our analytical data suggest that the extent of fatigue life reduction due to galvanisation is a function of the coating thickness and 
deemed to also depend on the number density of cracks in the coating. Our SEM inspection did not reveal significant differences in the number density of cracks between the NTG and HTG samples. Therefore, the shorter fatigue life of the NTG sample can be explained by the larger thickness of the retained zinc and porosity.

A comparison of the axisymmetric cases in Fig. 17 shows that the fatigue life decreases with increasing coating thickness. This effect can be explained using linear elastic fracture mechanics under the assumption of small scale yielding, where the strain energy stored in the coating layer contributes to the SIF in the crack tip. The Kitagawa diagram in Fig. 18 indicates a progressive nonlinear decrease of the fatigue threshold range with increasing coating thickness. The endurance limit knock-down is also a non-linear function of the initial crack size whose influence decreases with increasing $a_{i n i}$. This behaviour is in agreement with experimental observations of Bergengren and Melander (Ref 1), who reported a strong correlation between the coating thickness of hot-dip galvanised high-strength steel and its fatigue performance.

It is important that the model described in the present work is not restricted to the coating systems considered here, but is applicable to other systems as well. It therefore provides a useful tool to predict S-N curves of materials coated or surface treated using different processes. The model can potentially be extended to include effects of corrosive environments.

\section{Conclusions}

High cycle fatigue of threaded cylindrical high strength steel samples coated using either black oxidation, normal temperature galvanisation and high temperature galvanisation has been studied at a nominal stress amplitude of $90 \mathrm{MPa}$ in air and compared with that of uncoated samples. Based on experimental fatigue tests, microstructural examinations and numerical fatigue life predictions, the following conclusions are drawn: 
1. The fatigue performance of the HTG sample is slightly better than that of the NTG sample. The fatigue lifetime of each type of the hot dip galvanized samples is considerably lower than the lifetime of uncoated and black oxidised samples.

2. Cracks in the zinc coating are most likely caused by thermal effects during cooling and act as stress raisers, which can facilitate crack initiation in the steel. The presence of such cracks in the NTG and HTG samples caused a circumferential distribution of multiple crack initiation sites, which ultimately resulted in a crescent type fracture surface during fatigue tests. Conversely, the AM and BO samples exhibited a semi-circular fracture surface with fewer crack initiation sites.

3. The SIF in near-surface cracks is increased by the coating layer. The SIF is strongly affected by both the layer thickness and the ratio of the elastic moduli of the coating and the steel. It is shown analytically that the endurance limit decreases with increasing layer thickness.

4. The fatigue life of the NTG and HTG samples can be reasonably well predicted using the lower bound assumption of circumferential crack growth. The fatigue life of the AM and BO samples can be predicted using an upper bound assumption of single-sided crack growth.

Acknowledgements This work was supported by the Department of Wind Energy within the cross sectional activity programme. The authors acknowledge H.L. Toftegaard, J. Sjølin and L. Lorentzen for their technical assistance.

\section{References}

1. Y. Bergengren, and A. Melander, An experimental and theoretical-study of the fatigue properties of hot-dip-galvanized high-strength sheet steel, Int. J. Fatigue, 1992, 14, p $154-162$.

2. T. Nilsson, G. Engberg, H. Trogen, Fatigue properties of hot-dip galvanised steels, Scand. J. 
Metall., 1989, 18, p 166-175.

3. M. Oechsner, J. Beyer, F. Simonsen, P. Schaumann, R. Eichstädt, Experimental and analytical assessment of the fatigue strength of bolts with large dimensions under consideration of boundary layer effects, METEC \& 2nd European steel technology and application days (Düsseldorf, Germany) 2015, p 1-6.

4. P. Schaumann, R. Eichstädt, Fatigue assessment of high-strength bolts with very large diameters in substructures for offshore wind turbines, Proc. the $25^{\text {th }}$ Int. ocean and polar engineering conf. (Hawaii, USA), ISOPE, 2015, p 260-267.

5. P. Schaumann, R. Eichstädt, Ermüdung sehr großer HV-Schraubengarnituren, Stahlbau 2016, 85, p 604-611, in German.

6. DIN, Eurocode 3: Design of steel structures - Part 1-9: Fatigue, Standard, German version, DIN Deutsches Institut für Normung e.V. (Berlin, Germany) 2005, in German.

7. R. Schneider, Örtliche Bewertung der Schwingfestigkeit von Gewindeverbindungen, Darmstadt Techn. Univ., PhD thesis, 2010, in German.

8. CEN, Eurocode 3: Design of steel structures - Part 1-8: Design of joints, Standard, European Committee for Standardization, Management Centre (Brussels, Belgium) 2005.

9. CEN, High-strength structural bolting assemblies for preloading. System HRC. Bolt and nut assemblies with calibrated preload, Standard, BSI: FME/9 (London, UK) 2009.

10. Dassault Systèmes, Abaqus analysis user's manual, Vol. 6.16, 2016.

11. Dassault Systèmes, SolidWorks 3D mechanical CAD software, Reference Guide, 2016.

12. R. Krueger, Virtual crack closure technique: History, approach, and applications, Appl. Mech. Rev. 2004, 57 p 109-143.

13. NASA Johnson space center and southwest research institute, NASGRO Fracture mechanics and fatigue crack growth analysis software 4.0 Manual, 2002. 
14. R.G. Forman, S.R. Mettu, Behavior of surface and corner cracks subjected to tensile and bending loads in a Ti-6Al-4V alloy, Tech. Rep. NASA-TM-102165, NASA Johnson Space Center (Houston, USA) 1990.

15. J. Newman, A crack opening stress equation for fatigue crack-growth, Int. J. Fracture 24 (1984) 131-135.

16. R. Forman, V. Shivakumar, J. Cardinal, L. Williams, P. McKeighan, Fatigue crack growth database for damage tolerance analysis, Tech. Rep. DOT/FAA/AR-05/15, NASA Johnson Space Center (Houston, USA) 2005.

17. The MathWorks, Inc., MATLAB and Statistics Toolbox Release 2015a (Natick, USA) 2014.

18. G. Reumont, J.B. Vogt, A. Iost, J. Foct, The effects of an Fe-Zn intermetallic-containing coating on the stress corrosion cracking behavior of a hot-dip galvanized steel, Surf. Coat. Technol. 2001, 139, p 265-271.

19. J. Hutchinson, Z. Suo, Mixed-mode cracking in layered materials, Adv. Appl. Mech. 1992, 29, p63-191.

20. M. Thouless, Crack spacing in brittle films on elastic substrates, J. Am. Ceram. Soc. 1990, 73, p 2144-2146.

21. M. Thouless, E. Olsson, A. Gupta, Cracking of brittle films on elastic substrates, Acta Metall. Mater. 1992, 40, p 1287-1292.

22. Z. Xia, J. Hutchinson, Crack patterns in thin films, J. Mech. Phys. Solids 2000, 48, p 1107-1131.

23. J. Beuth, Cracking of thin bonded films in residual tension, Int. J. Solids Struct. 1992, 29, p $1657-1675$.

24. H. Tada, P. Paris, G. Irwin, The Stress Analysis of Cracks Handbook, Am. Soc. Mech. Eng. 
(New York, USA) 2000.

25. N. Pugno, R. Ruoff, Quantized fracture mechanics, Phil. Mag. 2004, 84, p 2829-2845.

26. N. Pugno, M. Ciavarella, P. Cornetti, A. Carpinteri, A generalized Paris' law for fatigue crack growth, J. Mech. Phys. Solids, 2006, 54, p 1333-1349.

27. M. Ashby, H. Shercliff, D. Cebon, Materials: engineering, science, processing and design, Elsevier Butterworth-Heinemann, 2014.

28. O. Basquin, The exponential law of endurance tests, ASTM, 1910, 10, p 625-630.

29. J. Dundurs, Discussion: Edge-bonded dissimilar orthogonal elastic wedges under normal and shear loading, J. Appl. Mech., 1969, 36, p 650-652.

30. Z. Zhang, O.V. Mishin, N. Tao, W. Pantleon, Microstructure and annealing behavior of a modified $9 \mathrm{Cr}-1 \mathrm{Mo}$ steel after dynamic plastic deformation to different strains, J. Nucl. Mater. 458 (2015) 64-69.

31. Z. Zhang, Y. Zhang, O.V. Mishin, N. Tao, W. Pantleon, D. Juul Jensen, Microstructural analysis of orientation-dependent recovery and recrystallization in a modified $9 \mathrm{Cr}-1 \mathrm{Mo}$ steel deformed by compression at a high strain rate, Metall. Mater. Trans. 2016, A47, p $4682-4693$.

32. M.F. Garwood, H.H. Zurburg, M.A. Erickson, Correlation of laboratory tests and service performance: Interpretation of tests and correlation with service, Am. Soc. Metals (Cleveland, USA) 1951.

33. D. Tullock, I. Reimanis, A. Graham, J. Petrovic, Deflection and penetration of cracks at an interface between 2 dissimilar materials, Acta Metall. Mater. 1994, 42, p 3245-3252.

34. A. Dimatteo, G. Lovicu, M. Desanctis, R. Valentini, M. Salvati, Influence of galvanizing process on fatigue resistance of microalloyed steels, Convegno Nazionale IGF XXI, (Cassino, Italy) 2011, p 283-291. 
35. P.P. Milella, Fatigue and corrosion in metals, Springer Milan, 2013. 
Table 1: Effective cross section $A_{\text {eff }}$, parameters of strength specified by the manufacturer, and the stress values adopted for the fatigue tests.

\begin{tabular}{ccccc}
\hline$A_{\text {eff }}$, & $\sigma_{y}$, & $\sigma_{u}$, & $\sigma_{m}$, & $\sigma_{a}$, \\
$\mathbf{m m}^{2}$ & $\mathbf{M P a}$ & $\mathbf{M P a}$ & $\mathbf{M P a}$ & $\mathbf{M P a}$ \\
\hline 227 & 900 & 1000 & 630 & 90 \\
\hline
\end{tabular}

Table 2: Material and fatigue crack growth parameters used for fatigue life predictions where the unit for $\mathrm{C}$ is $\mathrm{mm} /(\operatorname{cycle} \mathrm{MPa} \sqrt{\mathrm{mm}})$.

\begin{tabular}{|c|c|c|c|c|c|c|c|c|c|}
\hline Material & $\sigma_{y}$ & $K_{c}$ & $\Delta K_{1}$ & $C$ & $C_{t h}$ & $n$ & $p$ & $q$ & $\alpha$ \\
\hline & MPa & $\mathrm{MPa} \sqrt{m m}$ & $\mathrm{MPa} \sqrt{m m}$ & & & & & & \\
\hline ASTM A400 & 655 & 5907 & 70 & $1.231 \cdot 10^{-12}$ & 1.2 & 2.8 & 0.5 & 0.5 & 2.5 \\
\hline
\end{tabular}

Table 3: Basquin parameters and endurance limits obtained from numerical simulations for the three axisymmetric growth cases (Axi) and the single-sided growth case (Single).

\begin{tabular}{lccc}
\hline Case & $\boldsymbol{C}$, & $\boldsymbol{b}$ & $\boldsymbol{\sigma}_{e}$, \\
& MPa & MPa \\
\hline Axi $30 \mu \mathrm{m}$ & $3.99 \times 10^{3}$ & -0.333 & 50 \\
Axi $60 \mu \mathrm{m}$ & $3.98 \times 10^{3}$ & -0.335 & 42 \\
Axi $90 \mu \mathrm{m}$ & $3.89 \times 10^{3}$ & -0.336 & 39 \\
Single & $8.07 \times 10^{3}$ & -0.344 & 69 \\
\hline
\end{tabular}


Table 4: Critical SIFs calculated for the NTG and HTG samples based on different closed form solutions for the elastic thin film on thick substrate fracture presented in Ref 19-22.

\begin{tabular}{ccc}
$\boldsymbol{K}_{\boldsymbol{C}}^{N T G}$, & $\boldsymbol{K}_{\boldsymbol{C}}^{H T G}$, & Reference \\
$\mathbf{M P a} \sqrt{\boldsymbol{m}}$ & $\operatorname{MPa} \sqrt{\boldsymbol{m}}$ & \\
\hline 1.64 & 2.11 & 19 \\
1.00 & 0.92 & 20 \\
8.47 & 5.25 & 21 \\
0.93 & 0.91 & 22 \\
\hline
\end{tabular}

Page 31 


\section{Figure captions}

Fig 1 Representative samples used for tension-tension fatigue tests: (a) AM (uncoated thread) sample; (b) BO sample; (c) NTG sample; and (d) HTG sample.

Fig 2 Set-up of the fatigue test experiment: (a) testing machine; (b) specimen mounted in the jaws with a pair of extensometers used to record crack growth development.

Fig 3 The geometry of the samples with a thread notch allocated in the centre; the measured average shank diameter was $d=19.86 \mathrm{~mm}$, where $d_{2}$ indicates the diameter measured between the centres of the notch radii with $r=0.433 \mathrm{~mm}$.

Fig 4 Different 3D models used in this work: (a) with a threaded notch; (b) with a single circumferential notch consisting of two parts connected via tie constraints (magenta) and (c) an axisymmetric bolt model consisting of two parts connected via tie constraints (green). All loads applied at central master node are associated with a multiple point constraint (yellow).

Fig 5 Two different crack growth modelling approaches: (a) single-sided crack growth simulated in the 3D model; and (b) multisided crack growth simulated in the axisymmetric model. The dotted area indicates the crack face at an intermediate crack stage where initial crack length and the critical crack length are indicated by dashed lines.

Fig 6 Plan view of the single-sided fatigue crack growth integration scheme. The red line indicates the integration path in the crack growth direction (y), whereas the bold black line indicates the circular boundary of the circumferential notch.

Fig 7 Schematic illustrations of cracks in thin zinc coatings: (a) thermal strain induced cracks formed on a rigid substrate; (b) equi-biaxial tensile stress field in the coating; (c,d) a 
predominant circumferential crack penetrating through the coating into the steel substrate seen in the longitudinal section (c); and in the cross-section (d). Note that the coating thickness in this figure is exaggerated.

Fig 8 SEM images showing threads in the sample longitudinal section at different magnifications: (a) and (b) BO sample; (c) and (d) NTG sample; (e) and (f) HTG sample.

Fig 9 SEM image showing cracks both in the coating and in the steel (marked by arrows) in the thread root of the HTG sample.

Fig 10 Vickers hardness for the AM sample and three coated samples measured along the normalised distance, where 0 and 1 correspond to the surface and centre of the sample, respectively. For each data set, the first data point was obtained after grinding the thread to the root surface and by measuring $\mathrm{HV}$ in the thread root perpendicular to the root surface. The other data points were obtained in the polished longitudinal section of the samples.

Fig 11 Numbers of cycles to failure for the different samples tested in the present experiment. Three specimens were tested for each coated-sample series, while six specimens were tested for the AM sample.

Fig 12 Examples of fracture surfaces of the fatigue-tested samples: (a) AM sample; (b) BO sample; (c) NTG sample; and (d) HTG sample. AM and BO samples exhibit a typical halfmoon pattern, whereas the galvanised samples show a crescent type failure.

Fig 13 Strain range histories of both extensometers versus the number of cycles for (a) BO sample which shows the response from single-sided growth and (b) NTG sample with the response of multisided growth. 
Fig 14 Four non-zero stress components plotted along the perimeter of the notch root for thread lead-in, full thread turn and thread run-out. The wave length of the $S_{\mathrm{xx}}, S_{\mathrm{zz}}$ and $S_{\mathrm{xz}}$ component appears to be the same and corresponds to one half of the perimeter length of one full turn.

Fig 15 (a) Normalised von Mises stress $\sigma_{\mathrm{vM}}$ distributions in the radial direction obtained from the axisymmetric model (continuous lines) with the circumferential notch and the 3D model with the threaded notch (square markers); (b) model specimen geometry indicating the radial paths along cross sections at different offsets. Individual colours in (a) correspond to the colours in (b).

Fig 16 Maximum SIF $(\mathrm{MPa} \sqrt{\mathrm{mm}})$ contour plot as a function of the crack length and the transverse y-direction (see Fig.6). Only one half of the surface is depicted because of the symmetry. The surface ends at the critical crack length where the maximum SIF value reaches Kc.

Fig 17 Comparison of numerical simulations of axisymmetric (solid lines) and single-sided (dashed line) fatigue crack growth with the experimental data. The different colours of the solid lines correspond to different coating thicknesses.

Fig 18 Kitagawa diagram for a normalised stress range as a function of the cracked coating for different initial crack sizes; the dash-dotted line represents the asymptote for both zero initial crack size and zero coating thickness; the dashed line represents the asymptote for large cracks. 
Fig 19 Schematic illustrations of beach mark patterns observed on the fracture surface after fatigue failure: (a) due to mild stress concentrations; (b) due to severe stress concentrations; adapted from Ref 35. 


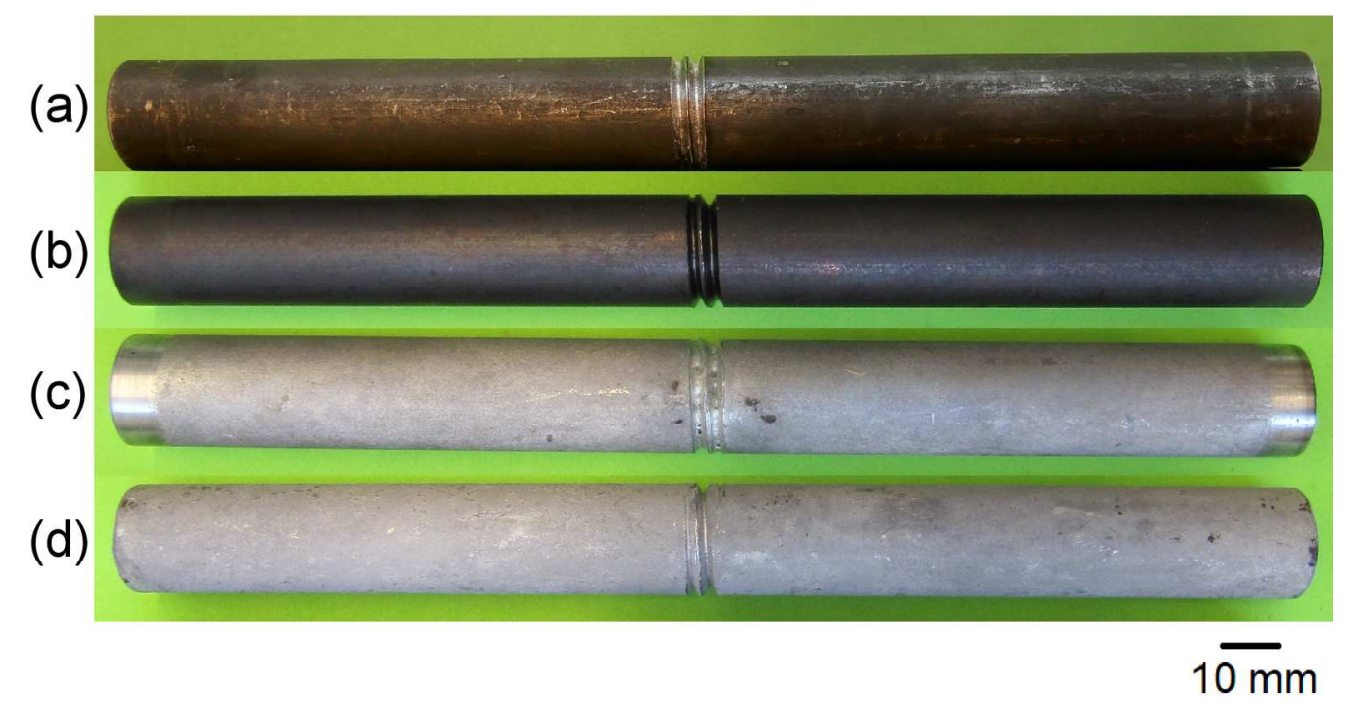

Fig 1 Representative samples used for tension-tension fatigue tests: (a) AM (uncoated thread) sample; (b) BO sample; (c) NTG sample; and (d) HTG sample.

$172 \times 90 \mathrm{~mm}(300 \times 300 \mathrm{DPI})$ 


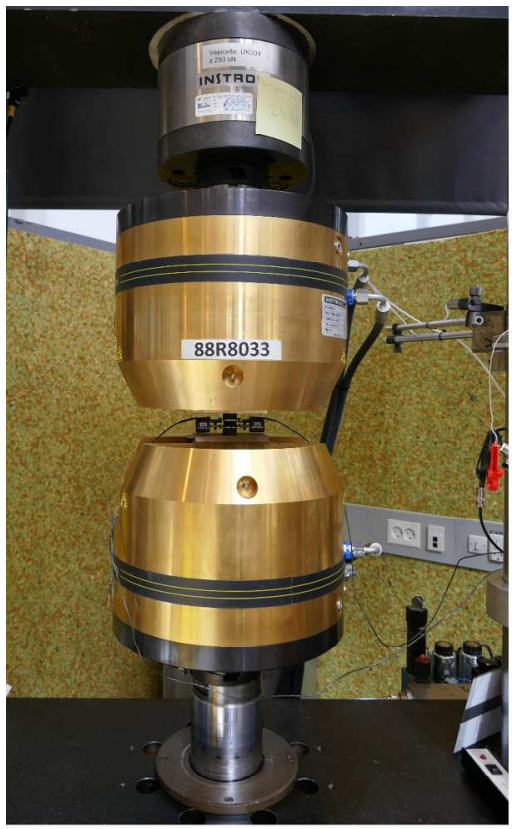

(a)

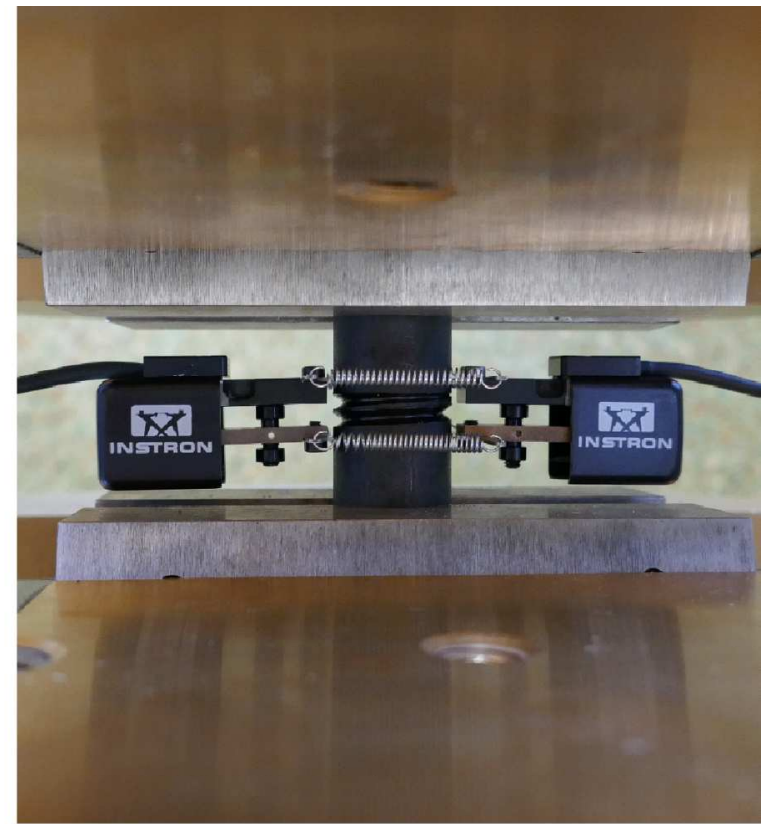

(b)

Fig 2 Set-up of the fatigue test experiment: (a) testing machine; (b) specimen mounted in the jaws with a pair of extensometers used to record crack growth development.

$173 \times 119 \mathrm{~mm}(300 \times 300$ DPI $)$ 
Fig 3 The geometry of the samples with a thread notch allocated in the centre; the measured average shank diameter was $d=19.86 \mathrm{~mm}$, where $\mathrm{d} 2$ indicates the diameter measured between the centres of the notch radii with $r=0.433 \mathrm{~mm}$. 
(a)

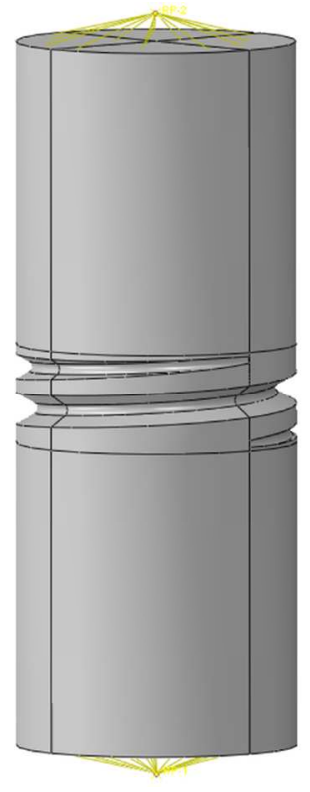

(b)

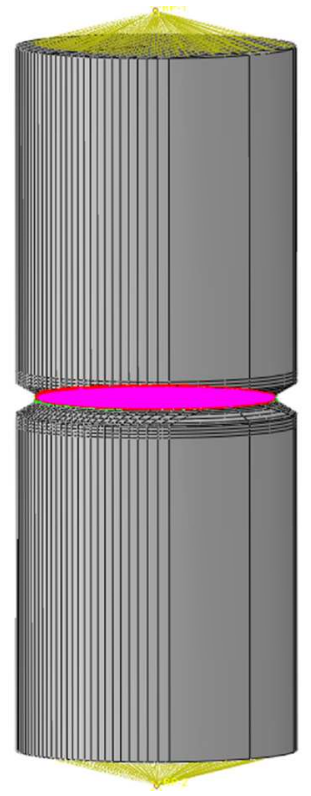

(c)

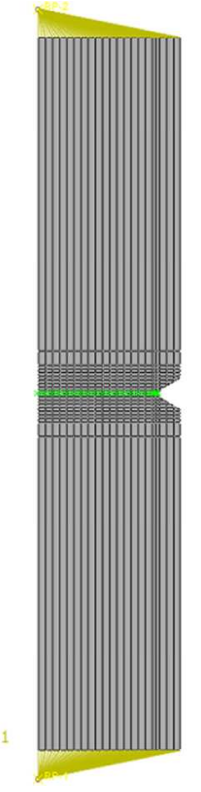

Fig 4 Different 3D models used in this work: (a) with a threaded notch; (b) with a single circumferential notch consisting of two parts connected via tie constraints (magenta) and (c) an axisymmetric bolt model consisting of two parts connected via tie constraints (green). All loads applied at central master node are associated with a multiple point constraint (yellow).

$104 \times 63 \mathrm{~mm}(300 \times 300 \mathrm{DPI})$ 
2

3

4

5

6

7

8

9

10

11

12

13

14

15

16

17

18

19

20

21

22

23

24

25

26

27

28

29

30

31

32

33

34

35

36

37

38

39

40

41

42

43

44

45

46

47

48

49

50

51

52

53

54

55

56

57

58

59

60
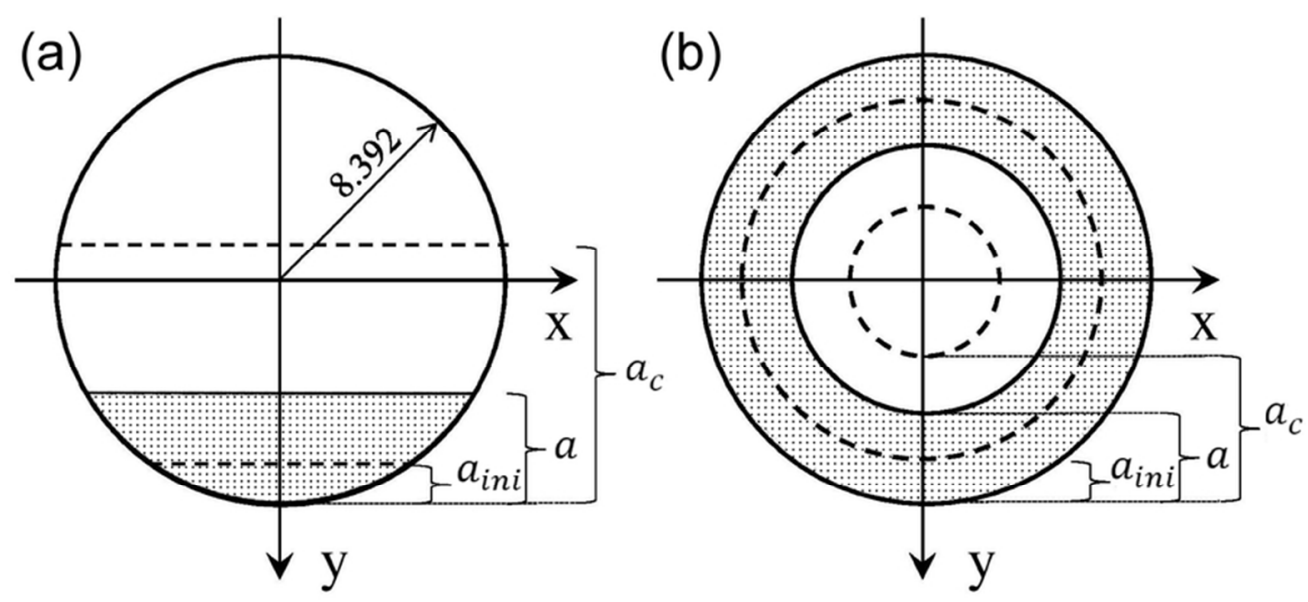

Fig 5 Two different crack growth modelling approaches: (a) single-sided crack growth simulated in the 3D model; and (b) multisided crack growth simulated in the axisymmetric model. The dotted area indicates the crack face at an intermediate crack stage where initial crack length and the critical crack length are indicated by dashed lines.

$37 \times 17 \mathrm{~mm}(600 \times 600 \mathrm{DPI})$ 


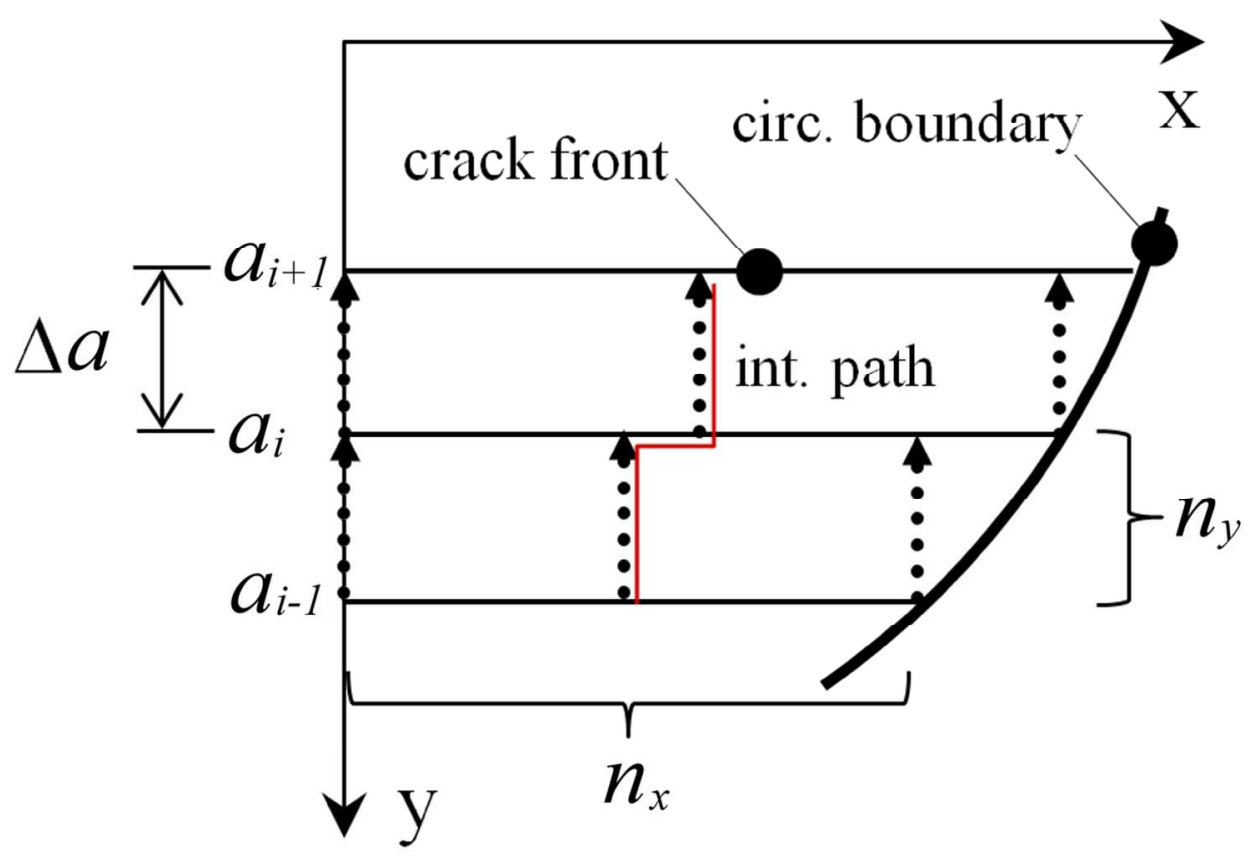

Fig 6 Plan view of the single-sided fatigue crack growth integration scheme. The red line indicates the integration path in the crack growth direction $(y)$, whereas the bold black line indicates the circular boundary of the circumferential notch.

$56 \times 37 \mathrm{~mm}(600 \times 600$ DPI $)$ 

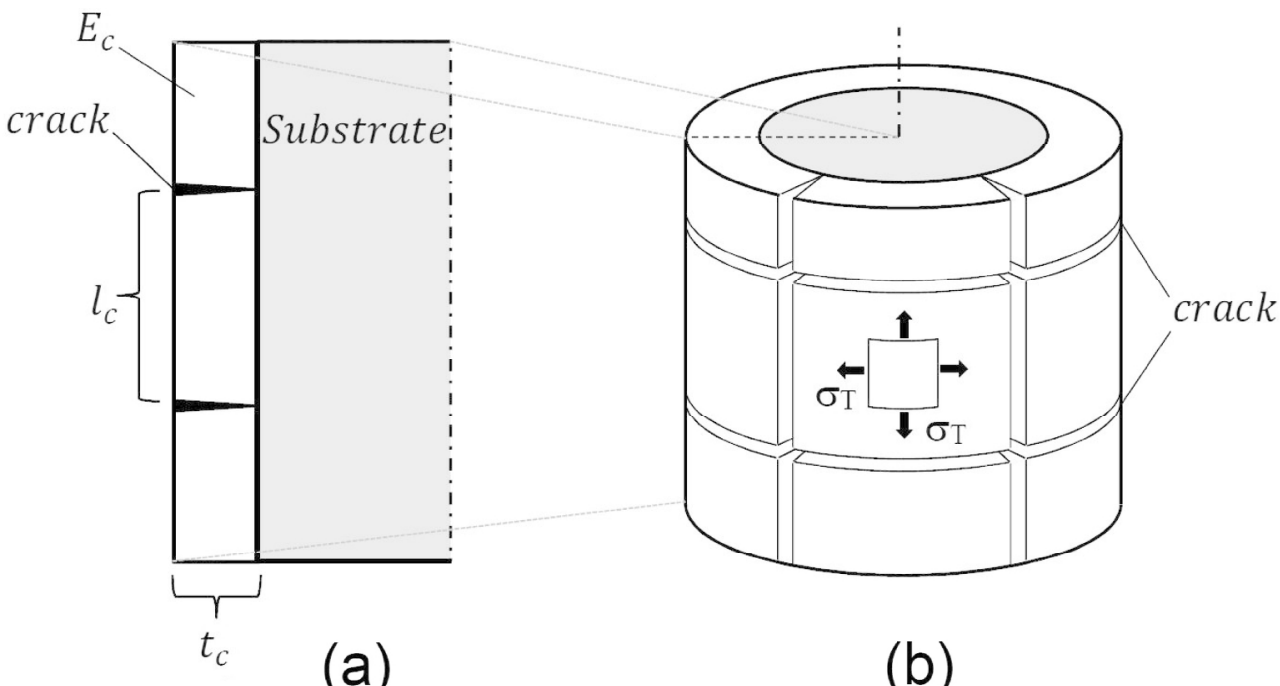

(b)

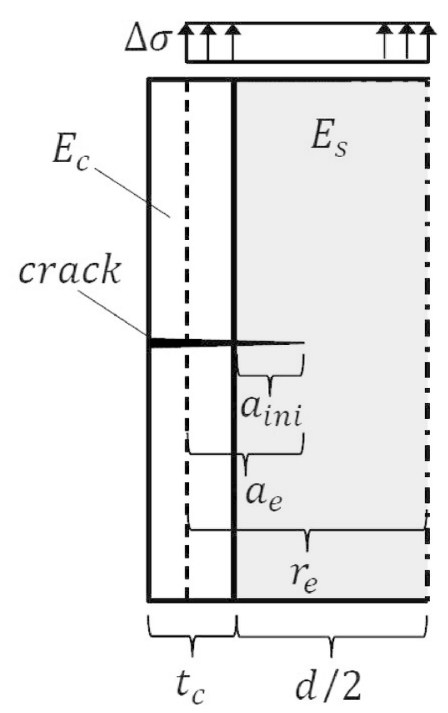

(c)

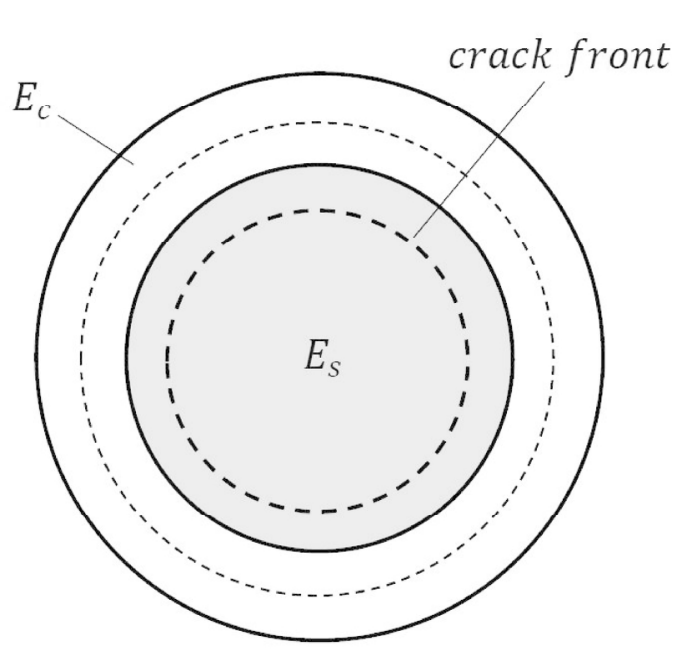

(d)

Fig 7 Schematic illustrations of cracks in thin zinc coatings: (a) thermal strain induced cracks formed on a rigid substrate; (b) equi-biaxial tensile stress field in the coating; $(c, d)$ a predominant circumferential crack penetrating through the coating into the steel substrate seen in the longitudinal section (c); and in the cross-section (d). Note that the coating thickness in this figure is exaggerated. 


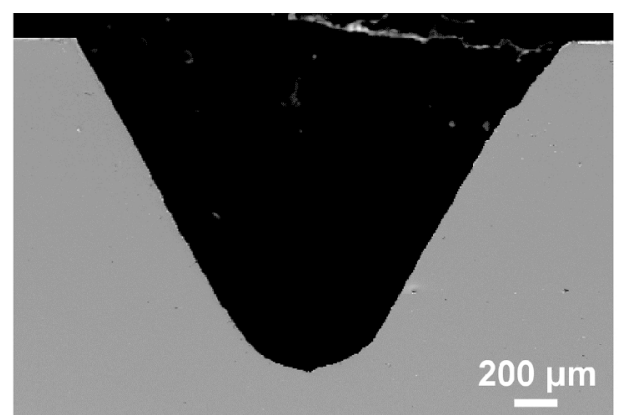

(a)

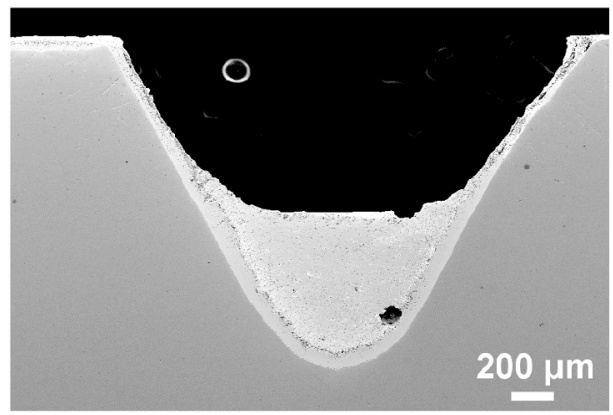

(c)

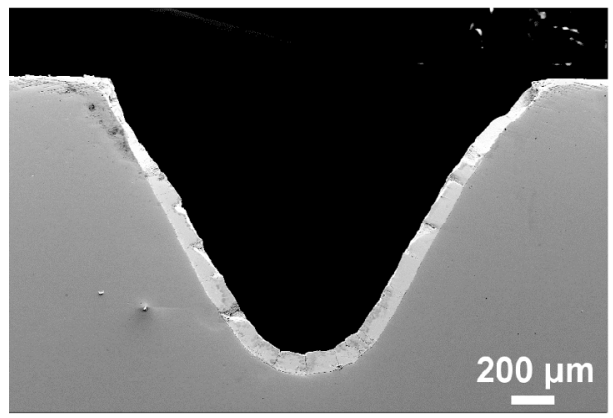

(e)

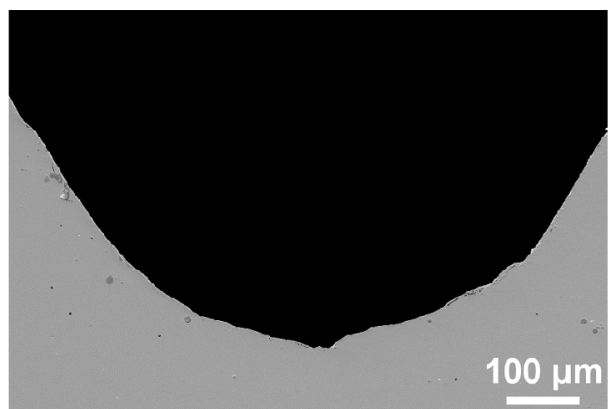

(b)

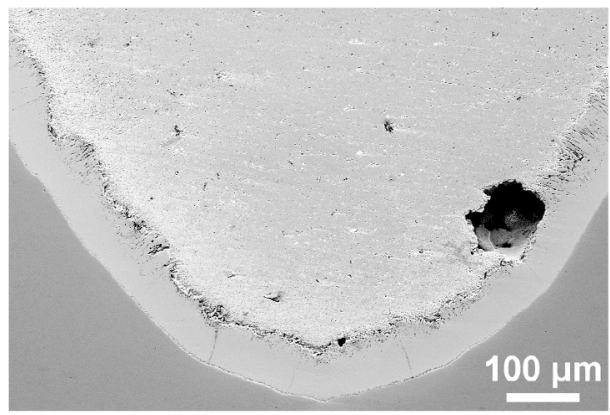

(d)

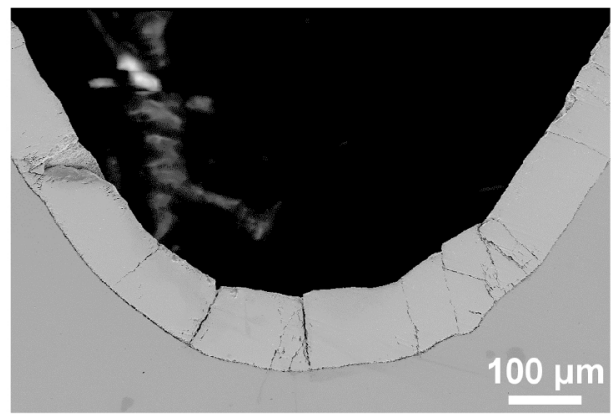

(f)

Fig 8 SEM images showing threads in the sample longitudinal section at different magnifications: (a) and (b) BO sample; (c) and (d) NTG sample; (e) and (f) HTG sample. 


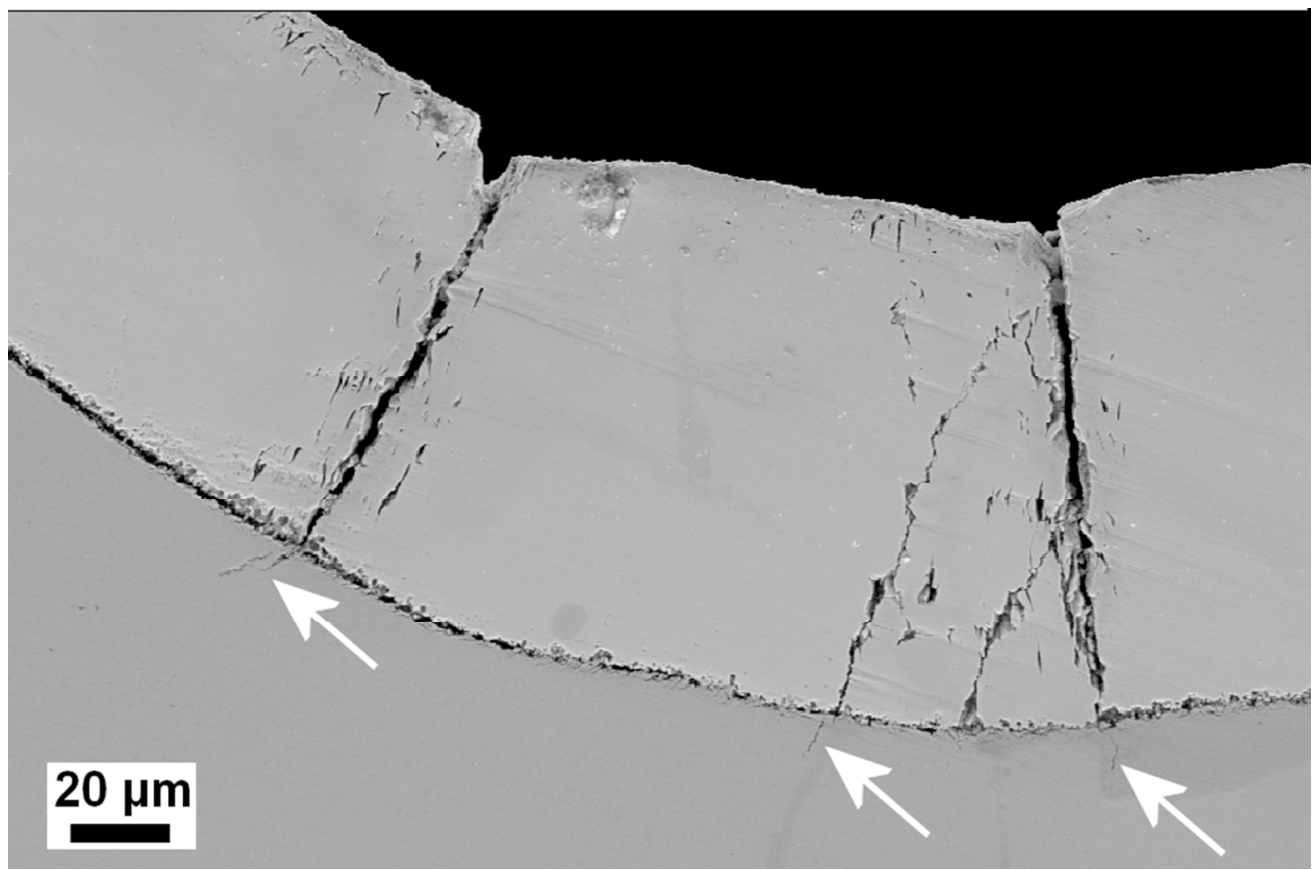

Fig 9 SEM image showing cracks both in the coating and in the steel (marked by arrows) in the thread root of the HTG sample.

\section{$83 \times 55 \mathrm{~mm}(300 \times 300$ DPI $)$}




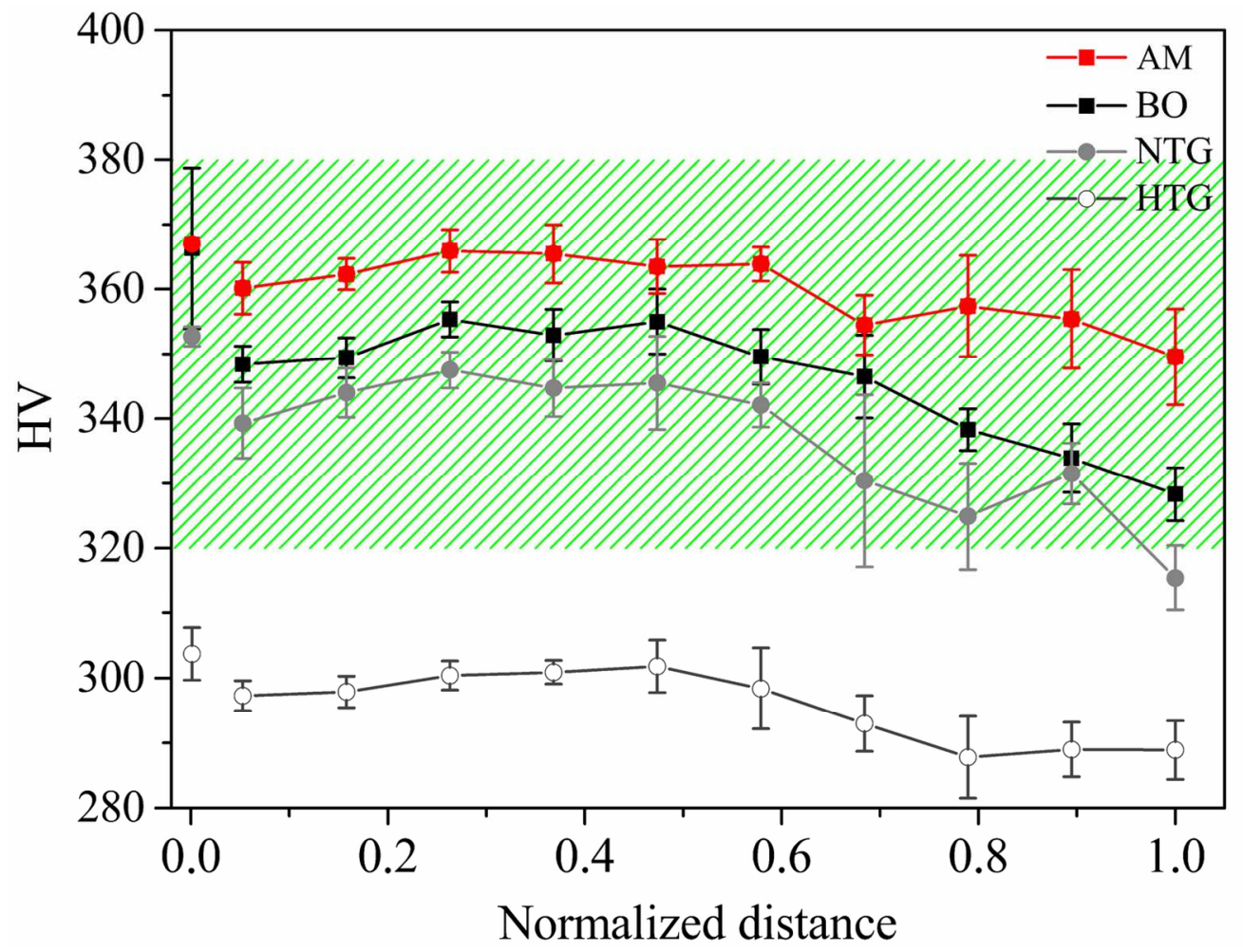

Fig 10 Vickers hardness for the AM sample and three coated samples measured along the normalised distance, where 0 and 1 correspond to the surface and centre of the sample, respectively. For each data set, the first data point was obtained after grinding the thread to the root surface and by measuring HV in the thread root perpendicular to the root surface. The other data points were obtained in the polished longitudinal section of the samples.

$66 \times 50 \mathrm{~mm}(600 \times 600 \mathrm{DPI})$ 


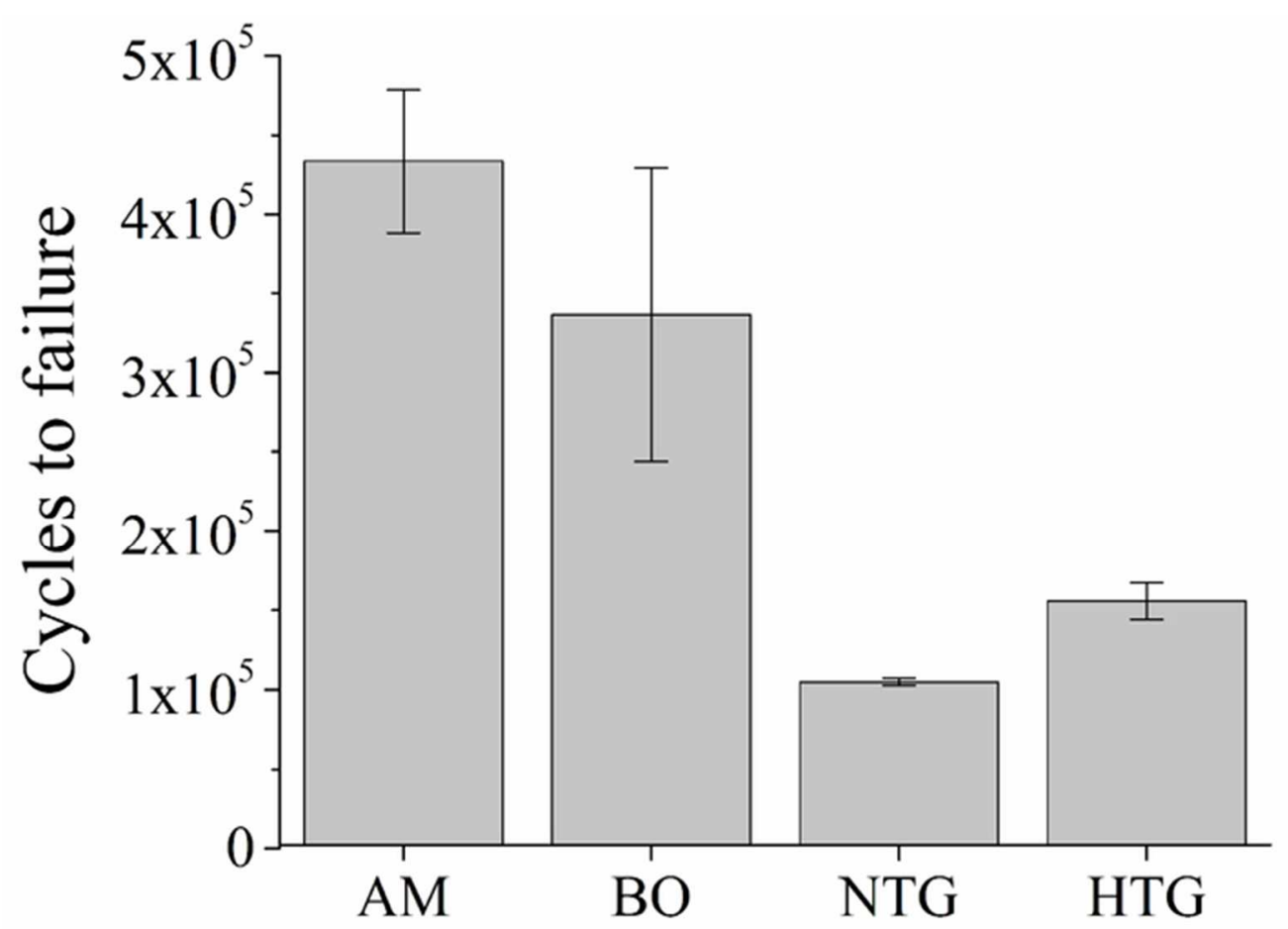

Fig 11 Numbers of cycles to failure for the different samples tested in the present experiment. Three specimens were tested for each coated-sample series, while six specimens were tested for the AM sample.

$59 \times 43 \mathrm{~mm}(300 \times 300$ DPI $)$ 


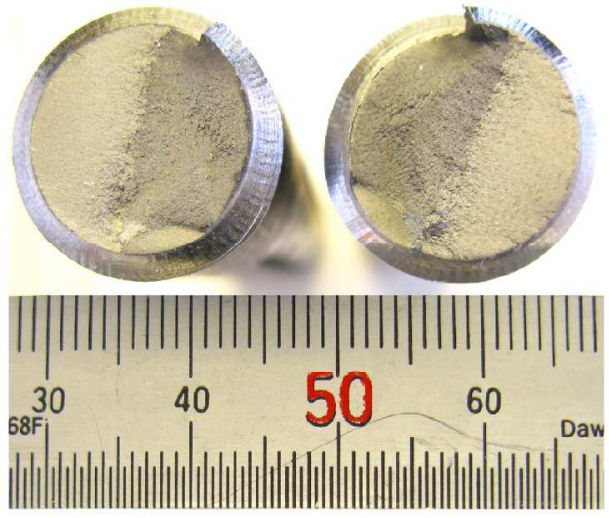

(a)
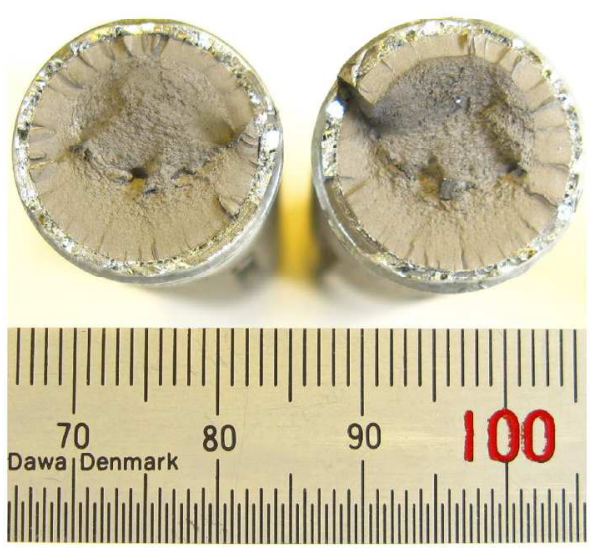

(c)

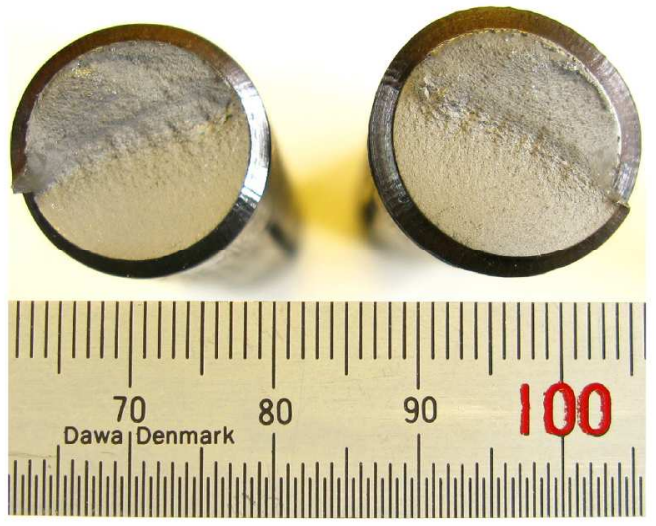

(b)

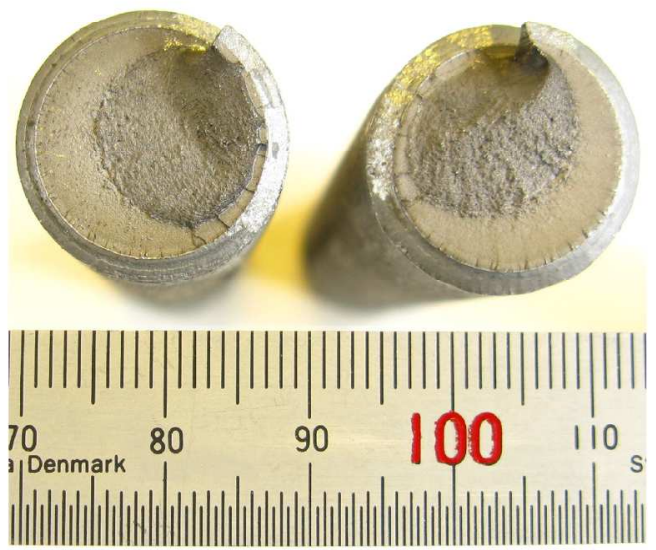

(d)

Fig 12 Examples of fracture surfaces of the fatigue-tested samples: (a) AM sample; (b) BO sample; (c) NTG sample; and (d) HTG sample. AM and BO samples exhibit a typical half-moon pattern, whereas the galvanised samples show a crescent type failure. 


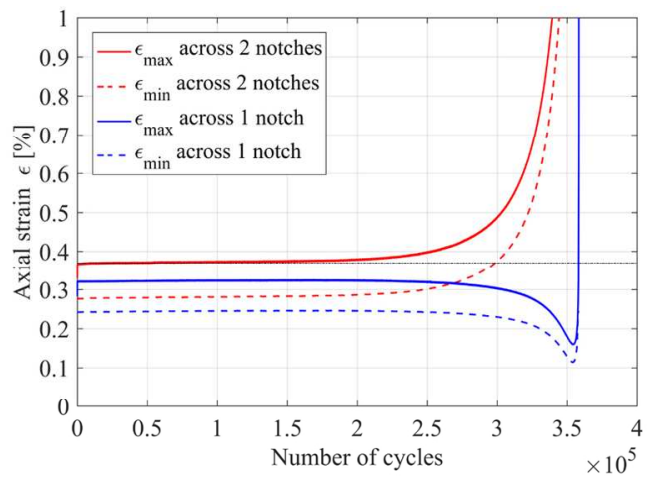

(a)

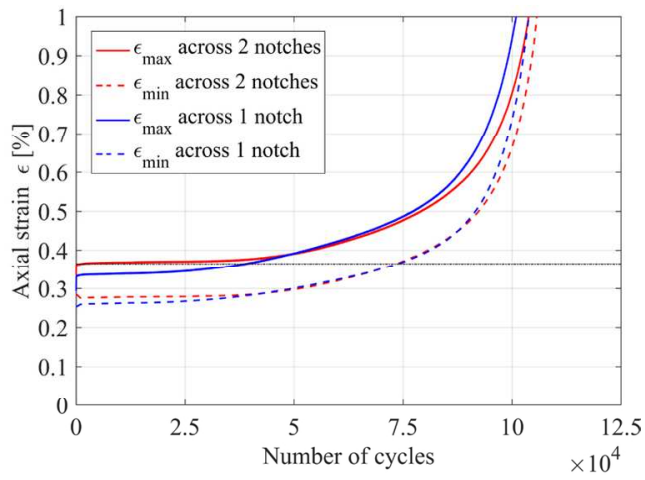

(b)

Fig 13 Strain range histories of both extensometers versus the number of cycles for (a) BO sample which shows the response from single-sided growth and (b) NTG sample with the response of multisided growth. 
Fig 14 Four non-zero stress components plotted along the perimeter of the notch root for thread lead-in, full thread turn and thread run-out. The wave length of the Sxx, Szz and Sxz component appears to be the same and corresponds to one half of the perimeter length of one full turn.

\section{$96 \times 53 \mathrm{~mm}(600 \times 600 \mathrm{DPI})$}




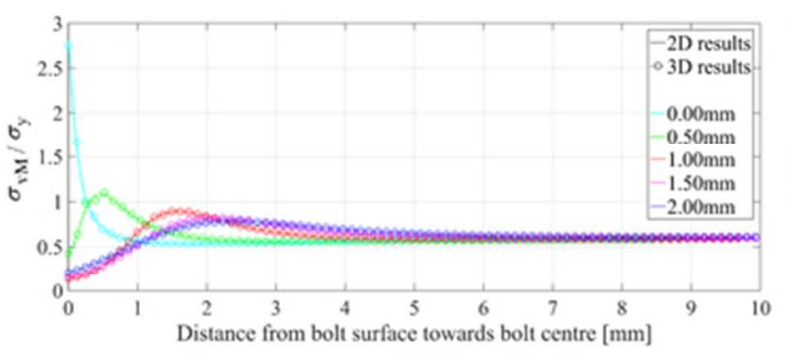

(a)

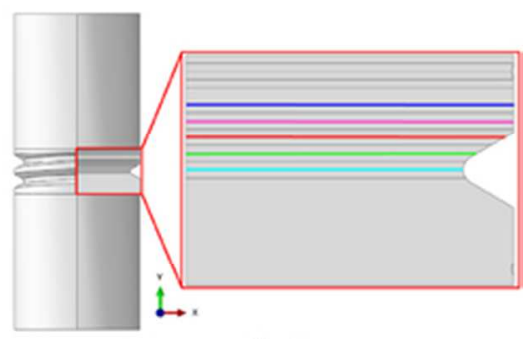

(b)

Fig 15 (a) Normalised von Mises stress $\sigma v M$ distributions in the radial direction obtained from the axisymmetric model (continuous lines) with the circumferential notch and the 3D model with the threaded notch (square markers); (b) model specimen geometry indicating the radial paths along cross sections at different offsets. Individual colours in (a) correspond to the colours in (b). 


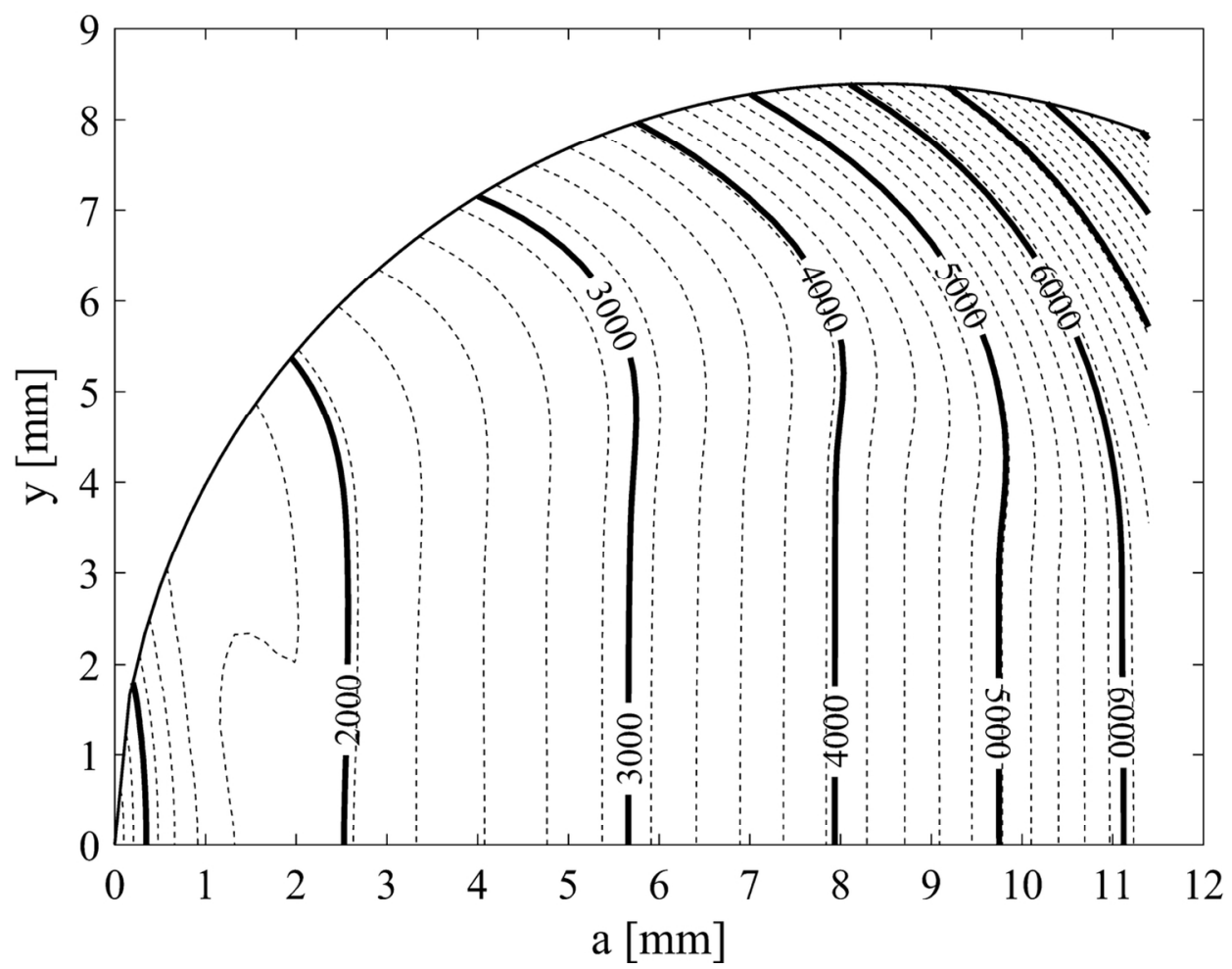

Fig 16 Maximum SIF (MPa $\sqrt{\mathrm{mm}}$ ) contour plot as a function of the crack length and the transverse $y$ direction (see Fig.6). Only one half of the surface is depicted because of the symmetry. The surface ends at the critical crack length where the maximum SIF value reaches Kc.

$62 \times 47 \mathrm{~mm}(600 \times 600$ DPI $)$ 


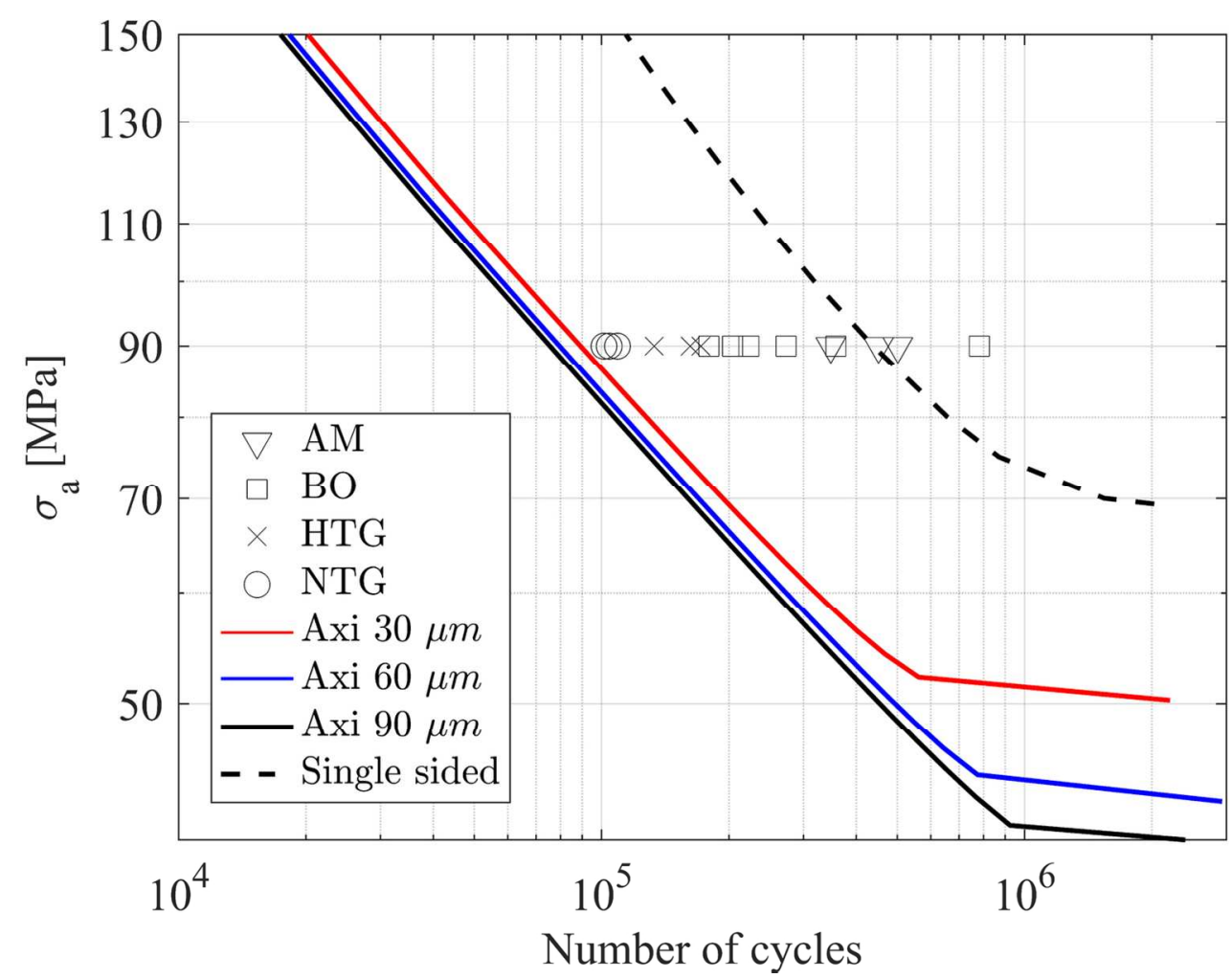

Fig 17 Comparison of numerical simulations of axisymmetric (solid lines) and single-sided (dashed line) fatigue crack growth with the experimental data. The different colours of the solid lines correspond to different coating thicknesses.

$65 \times 51 \mathrm{~mm}(600 \times 600 \mathrm{DPI})$ 
Fig 18 Kitagawa diagram for a normalised stress range as a function of the cracked coating for different initial crack sizes; the dash-dotted line represents the asymptote for both zero initial crack size and zero coating thickness; the dashed line represents the asymptote for large cracks.

\section{$62 \times 47 \mathrm{~mm}(600 \times 600 \mathrm{DPI})$}



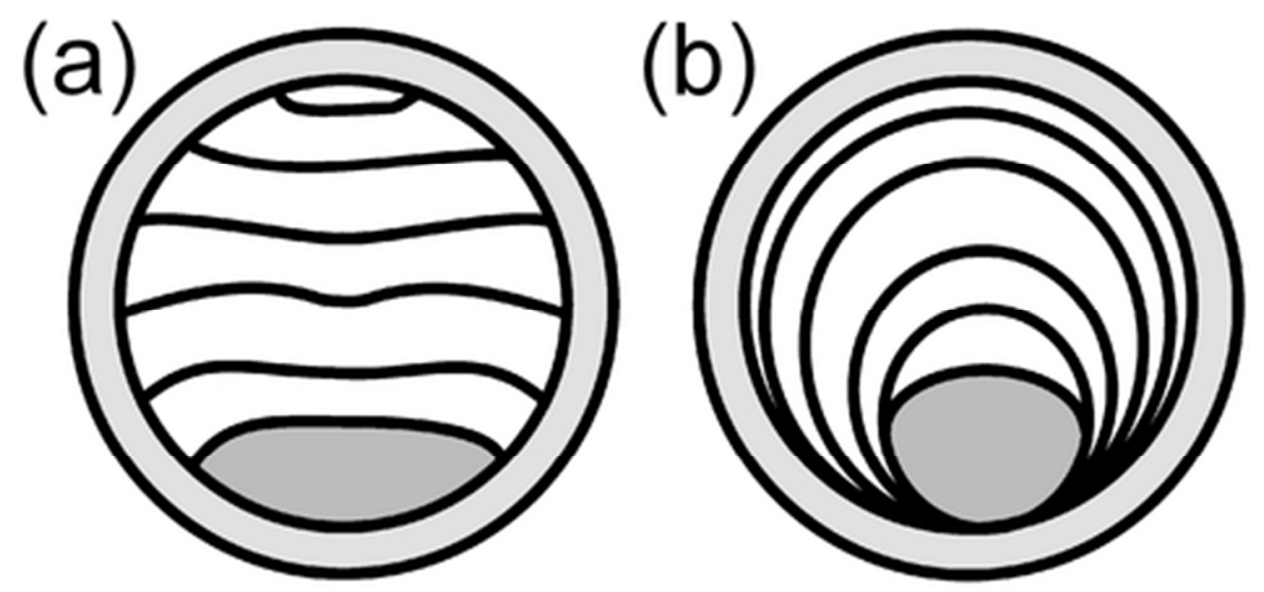

Fig 19 Schematic illustrations of beach mark patterns observed on the fracture surface after fatigue failure:

(a) due to mild stress concentrations; (b) due to severe stress concentrations; adapted from Ref 35.

$39 \times 18 \mathrm{~mm}(300 \times 300 \mathrm{DPI})$ 